\title{
The Effect of Voice Onset Time Differences on Lexical Access in Dutch
}

\author{
Petra M. van Alphen and James M. McQueen \\ Max Planck Institute for Psycholinguistics
}

\begin{abstract}
Effects on spoken-word recognition of prevoicing differences in Dutch initial voiced plosives were examined. In 2 cross-modal identity-priming experiments, participants heard prime words and nonwords beginning with voiced plosives with 12,6 , or 0 periods of prevoicing or matched items beginning with voiceless plosives and made lexical decisions to visual tokens of those items. Six-period primes had the same effect as 12-period primes. Zero-period primes had a different effect, but only when their voiceless counterparts were real words. Listeners could nevertheless discriminate the 6-period primes from the 12and 0-period primes. Phonetic detail appears to influence lexical access only to the extent that it is useful: In Dutch, presence versus absence of prevoicing is more informative than amount of prevoicing.
\end{abstract}

Keywords: voice onset time (VOT), Dutch plosives, spoken-word recognition, relevance of phonetic detail, cross-modal identity priming

The speech signal contains a wide variety of acoustic properties that encode the words that were intended by the speaker. To recognize these words, the listener must decode incoming speech by extracting phonetic information from the signal and mapping this onto stored lexical representations. Speech is highly variable, however, and not all acoustic information is equally relevant for word recognition. Whereas some of this information serves to cue particular perceptual distinctions and thus ought to help the listener to recognize words, other parts of the signal are less informative in this way and, at least with respect to lexical access, should be less influential. To function optimally, the word-recognition system must therefore distinguish more relevant from less relevant acoustic properties in the speech signal.

We tested this prediction by examining how variation in voice onset time (VOT) influences spoken-word recognition in Dutch. VOT is the primary cue to the phonological distinction between voiced and voiceless plosive consonants in initial position in Dutch (van Alphen \& Smits, 2004). We argue, however, that not all differences in VOT, even though they fall within the range of natural productions, are equally informative to listeners. The way in which VOT varies in Dutch gave us the opportunity to examine the effect on lexical access of a difference in VOT values that is extremely important for the distinction between voiced and voiceless plosives, and the effect of another difference in VOT values

Petra M. van Alphen and James M. McQueen, Max Planck Institute for Psycholinguistics, Nijmegen, the Netherlands.

Preliminary reports of this research were given at the Workshop on Speech Recognition as Pattern Classification, Nijmegen, the Netherlands, July 2001, and at the 142nd Meeting of the Acoustical Society of America, Fort Lauderdale, Florida, December 2001. We thank Joan Sereno for suggesting Experiment 3 to us, Roel Smits for his input throughout this project, and Anne Cutler and Paul Luce for comments on an earlier version of this article.

Correspondence concerning this article should be addressed to Petra M. van Alphen, who is now at the Department of Psychology, University of Amsterdam, Roetersstraat 15, 1018 WB Amsterdam, the Netherlands. E-mail: p.m.vanalphen@uva.nl that, though quantitatively the same, is less informative for the voicing distinction. Furthermore, we compare the effects of VOT variation on lexical access in Dutch with those in English and argue that the differences in the effects between the two languages can be explained by differences in the informational value of VOT in the two languages.

Listeners are capable of understanding words in different phonetic contexts, spoken by a large variety of speakers under many different listening conditions. The speech recognition system must therefore be flexible enough to extract lexically relevant information from the speech signal in spite of the variability in that signal. The recognition system is in fact relatively intolerant of phonemic mismatch between the speech signal and the information stored in lexical representations (e.g., Connine, Blasko, \& Titone, 1993; Connine, Titone, Deelman, \& Blasko, 1997; Frauenfelder, Scholten, \& Content, 2001; Marslen-Wilson, Moss, \& van Halen, 1996; Marslen-Wilson \& Zwitserlood, 1989; Milberg, Blumstein, \& Dworetzky, 1988). For example, mismatch in the initial phoneme of the word can inhibit lexical access (Marslen-Wilson \& Zwitserlood, 1989), and a mismatch later in the word can produce rapid deactivation of lexical candidates (Frauenfelder et al., 2001). The lexical level is also sensitive to fine-grained differences in the speech signal (see McQueen, 2005). Lexical access appears to be sensitive to a number of aspects of phonetic fine detail, such as mismatching formant transitions created by cross-splicing-for example, the initial consonant and vocalic portion of job spliced onto the final consonantal release portion of jog (Dahan, Magnuson, Tanenhaus, \& Hogan, 2001; Marslen-Wilson \& Warren, 1994; McQueen, Norris, \& Cutler, 1999; Streeter \& Nigro, 1979; Whalen, 1984, 1991). Other types of fine-grained detail that influence lexical access include information about syllable and word boundaries (Davis, Marslen-Wilson, \& Gaskell, 2002; Gow \& Gordon, 1995; Salverda, Dahan, \& McQueen, 2003; Shatzman \& McQueen, in press; Spinelli, McQueen, \& Cutler, 2003; Tabossi, Collina, Mazzetti, \& Zoppello, 2000) and cues to assimilation of place of articulation (Gow, 2002).

Further evidence that lexical activation is influenced by finegrained phonetic variation comes from studies investigating vari- 
ation in VOT. VOT is the interval between the release of the occlusion for a plosive consonant and the moment that the vocal cords start vibrating. In English, phonemically voiced plosives $(/ \mathrm{b}, \mathrm{d}, \mathrm{g} /)$ in initial position are usually produced with slightly positive VOTs, that is, with little or no aspiration (or occasionally with negative VOT), whereas voiceless plosives $(/ \mathrm{p}, \mathrm{t}, \mathrm{k} /)$ are produced with longer positive VOTs, that is, with aspiration. English listeners are very sensitive to VOT differences, because VOT and aspiration are the major cues for the voicing distinction in English (e.g., Lisker \& Abramson, 1970; Lotz, Abramson, Gerstman, Ingemann, \& Nemser, 1960; Miller \& Volaitis, 1989). Andruski, Blumstein, and Burton (1994) examined the influence on lexical access in English of VOT variation within the voiceless category of initial plosives. Half of the words had a voiced word competitor (e.g., pear, bear); the other half did not (e.g., king, ging). Three VOT conditions were created by either retaining the original VOT of the initial voiceless plosives or removing one or two thirds of that VOT. An identification study indicated that all three VOT variations were in general perceived as voiceless. The words in the three VOT conditions served as related primes in an associative priming task in which both prime and target were presented auditorily. Listeners were asked to decide whether the target (such as queen after the prime king) was a word or a nonword. Target lexical decisions were faster when targets were preceded by related primes, starting with various VOTs, than when they were preceded by unrelated primes. Critically, when the interstimulus interval (ISI) between prime and target was $50 \mathrm{~ms}$, lexical decisions to targets preceded by primes of which two thirds of the VOT was removed were significantly slower than lexical decisions to the same targets preceded by primes with unaltered VOT. Although lexical decisions to targets preceded by primes with voiced word competitors were overall slower than to targets preceded by primes without such competitors, the competitor environment seemed not to influence the effects of VOT variation. The results of Andruski et al. indicate that in English, quantitative variations in the positive VOTs of initial voiceless plosives affect the degree of activation of lexical candidates starting with voiceless plosives. Similar effects have been observed by Utman, Blumstein, and Burton (2000), using the identity priming task, and by McMurray, Tanenhaus, and Aslin (2002), using eye tracking.

These studies show that lexical access in English is sensitive to VOT variation. If one also considers the other research mentioned above on the influence of fine phonetic detail on lexical access, one might thus suppose that all phonetic detail influences lexical activation and thus predict that quantitative variation in VOT in Dutch will also influence lexical access. We argue here, however, that this view is too simplistic. We suggest that the influence of phonetic detail on lexical activation depends on the informational value of the current input. As a consequence, we predict that quantitative differences in VOT in Dutch will have less of an effect on lexical access than they do in English.

In Dutch, the main perceptual cue for the distinction between voiced and voiceless initial plosives is the presence or absence of prevoicing (van Alphen \& Smits, 2004). Prevoicing is the presence of vocal cord vibration during the consonantal closure, and it corresponds to a negative VOT, because the moment that the vocal cords start vibrating falls before the moment of the release of the occlusion. One of the requirements for the production of vocal cord vibration is that sufficient transglottal pressure is achieved and maintained to allow the vocal cords to vibrate. This is relatively difficult when all outgoing air pathways are closed, as is the case with plosive consonants. Van Alphen and Smits (2004) argued that this makes the production of prevoicing relatively vulnerable. They found that the duration of prevoicing indeed varies considerably within and among speakers and that no less than $25 \%$ of the voiced tokens in their sample were produced without prevoicing. ${ }^{1}$ Their perception data showed, however, that when a plosive was produced with prevoicing, and irrespective of the amount of prevoicing, listeners always perceived the plosive as voiced. This was true for both $/ \mathrm{b} /$ and $/ \mathrm{d} /$. (Note that the velar plosive $/ \mathrm{g} /$ is marginal in Dutch, as it occurs only in loan words. The velar plosive was therefore not tested by van Alphen and Smits and is not examined here.) When listeners had to identify voiced plosives that were produced without prevoicing, the majority of these unprevoiced tokens were still perceived as being voiced, as a result of other cues in the signal. A regression tree analysis revealed that perception of labial, but not alveolar, plosives without prevoicing as voiced depended primarily on the fundamental frequency (F0) movement immediately after the burst, whereas perception of alveolar, but not labial, plosives without prevoicing as voiced depended on the spectral center of gravity of the burst. The influence of these secondary cues was, however, weak in comparison to the influence of prevoicing on perception. The role of prevoicing thus appears to be asymmetric: The presence of any periods of prevoicing unmistakably signals that the plosive is voiced, but it is not a prerequisite for a plosive to be perceived as being voiced.

In summary, the duration of prevoicing of Dutch initial plosives varies considerably, and in line with this, the exact duration of prevoicing seems not to affect substantially the strength of the evidence that a plosive is voiced. Thus, the exact duration of prevoicing is not important for the distinction between voiced and voiceless plosives. The information that helps the listener to distinguish between voiced and voiceless plosives lies in the presence or absence of prevoicing. When prevoicing is present, the plosive is always perceived as voiced. Deleting the prevoicing of voiced plosives therefore reduces the probability that the plosive is voiced (although the plosive will in general still be heard as voiced).

The study by van Alphen and Smits (2004) examined the effects of natural prevoicing variation in Dutch on phoneme identification but not the degree to which lexical activation is affected by this kind of VOT variation. The present study examined the effect of two prevoicing differences on lexical access: the difference between 12 and 6 periods of prevoicing and that between 6 and 0 periods of prevoicing. Both differences are of the same size, namely 6 periods of prevoicing, and both vary along the VOT scale within the natural range of VOT variation. But the former involves only a difference in the duration of the prevoicing, whereas the

\footnotetext{
${ }^{1}$ Note that it could be the case that part of the prevoicing variation obtained by van Alphen and Smits (2004) was due to variation in speaking rate. In a new analysis of the van Alphen and Smits data, however, we found that the correlation between vowel duration and prevoicing duration was very low $(-.073)$, even when we selected only the tokens that were produced with prevoicing $(-.031)$. Although speaking rate may affect prevoicing duration, these low correlations indicate that the variation in prevoicing found in van Alphen and Smits's study was not caused by differences in speaking rate.
} 
latter also involves the difference between the presence and absence of prevoicing. The findings of van Alphen and Smits suggest that the difference between 12 and 6 periods of prevoicing will not substantially affect the probability that the plosive is voiced. In contrast, the difference between 6 and 0 periods of prevoicing will affect that probability, as deleting the prevoicing takes away a major cue to the voicing of the plosive. We therefore predicted that the difference between 6 and 0 periods of prevoicing would affect the degree of activation of lexical candidates. In contrast, we predicted that the difference between 12 and 6 periods of prevoicing would result in no or at least smaller effects on the activation of lexical candidates. We thus predicted a different effect for variation in negative VOT in Dutch than the effects found for variation in positive VOT in English (Andruski et al., 1994). In English, graded effects on lexical access were found when the duration of VOT varied. In Dutch, however, we expected to find only weak or no effects on lexical access of variation in VOT. In contrast, we expected to find graded effects as a result of prevoicing deletion in Dutch. Note that in English deleting the positive VOT changes the plosive from voiceless into voiced, whereas in Dutch deleting the negative VOT does not reliably change the phonemic percept.

As van Alphen and Smits (2004) showed, the absence of prevoicing in Dutch occurs in both voiced and voiceless plosives. It is therefore possible that plosives without prevoicing would also affect activation of lexical competitors starting with voiceless plosives. To test this, in the present study we investigated the two types of prevoicing variation in plosives at the beginning of both words and nonwords that either had a word competitor starting with a voiceless plosive or did not. English examples of these materials are the words blue (where plue is a nonword) and bear (with the voiceless lexical competitor pear) and the nonwords blem (plem is also a nonword) and brince (with the lexical competitor prince). Two priming experiments and a discrimination experiment were carried out using Dutch versions of these four types of item (see Table 1). In Experiment 1 we examined the influence of spoken primes varying in prevoicing on recognition of visual targets beginning with voiced plosives (i.e., Dutch versions of blue, bear, blem, and brince). In Experiment 2 we used the same primes but measured recognition of the voiceless counterparts of the Experiment 1 targets (i.e., Dutch versions of plue, pear, plem, and prince). Experiment 3 established that listeners can discriminate between the primes used in the first two experiments.

The cross-modal identity-priming task was used in Experiments 1 and 2. Previous experiments using this task have shown that when primes are phonologically identical to the targets, a significant facilitatory effect is observed (Marslen-Wilson, Nix, \& Gaskell, 1995; Spinelli et al., 2003), but no such effects are found when prime and target differ only in their initial sounds (Cutler, van Ooijen, \& Norris, 1999; Radeau, Segui, \& Morais, 1994). This suggests that the facilitation measured in this task is mainly due to activation at the lexical level rather than activation at prelexical levels of processing. In contrast, results of experiments using the within-modality identity-priming task (e.g., in Utman et al., 2000) suggest that this task may in part reflect prelexical effects (i.e., effects due to the overlap of sublexical components of primes and targets rather than lexical overlap; Slowiaczek, McQueen, Soltano, \& Lynch, 2000). We therefore avoided this version of the priming paradigm. Because the cross-modal version appears to be sensitive to subtle variation in the initial phoneme (Spinelli et al., 2003), we assumed it would be sensitive to differences in prevoicing in initial plosives.

\section{Experiment 1}

Participants were presented with visual target words and nonwords starting with voiced plosives (hereafter, we refer to these as the voiced targets, even though voicing refers to the way the plosives are spoken, not how they are written; see Table 1). These were preceded by identical spoken primes starting with voiced plosives with different prevoicing durations (the voiced primes, with 12,6 , or 0 periods of prevoicing). Note that we use the term identical when prime and target were the same words; we do not mean that prime and target are identical in the physical sense. There was also a priming condition in which primes were identical to the targets, except for the initial plosive, which was voiceless instead of voiced (hereafter, the voiceless primes), and a priming condition in which primes were phonologically unrelated to the

Table 1

Design of Experiments 1 and 2

\begin{tabular}{|c|c|c|c|c|}
\hline \multirow[b]{2}{*}{ Priming condition } & \multicolumn{4}{|c|}{ Lexical status condition } \\
\hline & Blue & Bear & Blem & Brince \\
\hline \multicolumn{5}{|c|}{ Prime } \\
\hline Prevoicing 12 & blauw (blue) & beer (bear) & blem & brins \\
\hline Prevoicing 6 & blauw (blue) & beer (bear) & blem & brins \\
\hline Prevoicing 0 & blauw (blue) & beer (bear) & blem & brins \\
\hline Voiceless & plauw & peer (pear) & plem & prins (prince) \\
\hline Unrelated & buurt (neighborhood) & breuk (fraction) & burf & bleug \\
\hline \multicolumn{5}{|c|}{ Target } \\
\hline Voiced (Experiment 1) & blauw (blue) & beer (bear) & blem & brins \\
\hline Voiceless (Experiment 2) & plauw & peer (pear) & plem & prins (prince) \\
\hline
\end{tabular}

Note. Examples of a prime and a target are given for each combination of priming condition and lexical status condition. English translations of real words appear in parentheses. 
targets (the unrelated primes). We predicted that plosives with 12 and 6 periods of prevoicing would be perceived as voiced plosives and that deleting the prevoicing would result in less clear voiced plosives. Nevertheless, we predicted that these unprevoiced plosives would in general still be perceived as being voiced. These predictions were tested in a phoneme identification experiment.

We expected to find the following patterns in the priming experiment. First, we expected to find a facilitatory effect when the primes were identical to the targets (i.e., with the 12- and 6-period voiced primes) in comparison to unrelated primes. We expected to find only a small or no difference between the 12- and 6-period voiced primes. Second, we predicted that we would find no facilitatory effect when primes and targets differed only in the initial phoneme (i.e., with the voiceless primes). Third, if it is the case that the absence of prevoicing significantly affects lexical access, the 0 -period voiced primes should result in a smaller facilitatory effect than voiced primes with prevoicing. But the 0 -period voiced primes should lead to more facilitation than the voiceless primes, as voiced primes without prevoicing are expected to be perceived as voiced. We thus expected the pattern for the 0-period voiced primes to fall between that for the voiced primes with prevoicing and that for the voiceless primes.

The use of both words and nonwords beginning with voiced stops allowed us to examine lexical involvement on any effects of prevoicing variation. Unprevoiced plosives are likely to contain enough remaining cues for the plosive to still be perceived as voiced (van Alphen \& Smits, 2004), but the absence of prevoicing will shift the voiced plosive closer to the voiceless category in perceptual space. It is therefore very likely that items starting with voiced plosives without prevoicing will substantially activate any word candidates starting with the voiceless counterpart. To test this possibility, we chose targets (and thus voiced primes) that were either words or nonwords with or without voiceless word competitors (see Table 1). If it is indeed the case that voiceless word competitors are strongly activated by voiced primes without prevoicing, a difference should be found between the conditions with voiceless word competitors and those without such competitors. We expected that the effect of the voiceless word competitor would be strongest when the voiced target was a nonword, because the voiceless word would then be the only strongly activated lexical candidate. In the condition in which both the voiced target and the voiceless competitor were words, the two candidates were expected to compete with each other for recognition. In that case we expected the voiced word candidate to win, as we predicted that voiced plosives without prevoicing would in general still be perceived as voiced. If the voiceless word competitor is not substantially activated when listeners hear primes starting with these plosives, no differences should be found as a function of the lexical status of the counterpart.

\section{Method}

Participants. Sixty volunteers from the Max Planck Institute (MPI) participant pool were paid to take part. All were native speakers of Dutch, and none reported any hearing loss.

Materials. Forty pairs of Dutch monosyllables in each of four lexical status conditions were selected, which consisted of an item starting with a voiced plosive and a matched item that was identical except that its initial plosive was voiceless. These pairs are listed in the Appendix. The blue condition contained pairs for which the voiced members were words and the voiceless members were nonwords: for example, blauw-plauw (blauw means blue, and plauw is not a word in Dutch). The bear condition contained pairs for which both voiced and voiceless members were words: for example, beer-peer (bear-pear). The blem condition contained pairs for which both members were nonwords: for example, blem-plem. Finally, in the brince condition, the voiced members were nonwords and the voiceless members were words: for example, brins-prins (brins is not a word in Dutch, and prins means prince). Each condition consisted of 27 pairs starting with a $/ \mathrm{b} /$ and a $/ \mathrm{p} /$ and 13 pairs starting with a /d/ and a /t/. This ratio of labial and alveolar plosives was determined by the number of possible items in the bear condition. The mean frequency of the voiced words of the blue pairs was 35 per million words (from the CELEX lexical database; Baayen, Piepenbrock, \& Gulikers, 1995). The voiceless members of the brince pairs had a mean frequency of 36 per million words. The frequency of the word members was thus matched across the blue and brince conditions. The mean frequencies of the voiced and voiceless members of the bear pairs were, respectively, 14 and 15 per million words.

There were five priming conditions: prevoicing 12 , prevoicing 6 , prevoicing 0 , voiceless, and unrelated. In the first three conditions, the primes consisted of the voiced members of the pairs. For each target these three different primes were acoustically identical, except for the duration of the prevoicing, which varied systematically among these conditions (respectively, 12,6 , or no periods of prevoicing). In this way we controlled for any possible speaking rate effects, as vowel duration was kept constant across conditions. In the voiceless priming condition, the primes were the voiceless members of the pairs. In the unrelated priming condition, primes were unrelated to the targets but started with the same voiced plosives (labial or alveolar) as the targets. The lexical status of each unrelated prime was identical to the lexical status of the voiced prime for that target, but the unrelated primes had no voiceless word competitors.

In addition, there were 320 unrelated prime-target pairs that served as fillers. These pairs consisted of 40 nonword-prime/nonword-target pairs, 120 nonword-prime/word-target pairs, 120 word-prime/nonword-target pairs, and 40 word-prime/word-target pairs. The fillers consisted of both mono- and polysyllabic items.

Stimulus construction. All items and fillers were recorded several times by a male native speaker of Dutch in a sound-attenuated booth onto digital audiotape (sampling at $48 \mathrm{kHz}$ with 16-bit resolution). The utterances were redigitized at a sample rate of $16 \mathrm{kHz}$ using the speech-editing system Xwaves. For the three prevoicing conditions and the unrelated condition, tokens were chosen that were produced clearly and with prevoicing. Subsequently, the original prevoicing of each related prevoiced item was replaced by 12,6 , or 0 periods of prevoicing (corresponding to 136,68 , or $0 \mathrm{~ms}$ of prevoicing for $/ \mathrm{b} /$ and to 138,69 , and $0 \mathrm{~ms}$ of prevoicing for $/ \mathrm{d} /$ ), to create the three different prevoicing conditions. The first full period of prevoicing plus the lead-in (of $7 \mathrm{~ms}$ ) of a natural token of the word /bus/ (bus) was chosen as the first period of prevoicing for the two conditions with prevoicing (12 and 6 periods) for all items starting with a labial plosive. Similarly, the last prevoicing period of that same token of /bus/ always served as the last prevoicing period in these two conditions. The intervening prevoicing periods ( 10 or 4 ) were chosen from that /bus/ token, such that the result sounded natural. The same procedure was applied to create the alveolar prevoicing 12 and prevoicing 6 conditions, but now the prevoicing periods were all derived from the same natural token of the word /dus/ (thus). To control for any splicing effects, the prevoicing of each of the unrelated primes was also replaced by 6 periods of prevoicing. The voiceless primes were natural productions of the voiceless counterparts of the targets.

Procedure. The experiment had two parts. The first consisted of the cross-modal identity-priming task. Primes were presented binaurally over headphones at a comfortable listening level. The target was presented visually $200 \mathrm{~ms}$ after the onset of the plosive burst of the prime, such that the target appeared on the screen during the prime. Note that it is impossible to use a target presentation point at which the amount of information 
perceived by the listener is equal across conditions (as the difference in prevoicing is a temporal difference). With the current stimulus onset asynchrony (SOA), listeners nevertheless had always heard the prevoicing and burst of the initial plosive before the target appeared. Previous research has suggested that presenting the target in a cross-modal identity-priming task at the onset of the prime might be too early to measure differential lexical activation across conditions, and presenting the target at the offset of the prime may be too late (van der Lugt, 1999). Presenting the target halfway through the prime results in differential priming effects (Spinelli et al., 2003). The targets in the present experiment were therefore presented during the primes. Note that Andruski et al. (1994) found significant differences in a unimodal associative priming task when targets were presented $50 \mathrm{~ms}$ after the offset of the primes but not later. This suggests that graded effects on lexical access have a limited time course. The unimodal task used by Andruski et al., however, made it impossible for them to present the target any earlier. The cross-modal priming task used here allowed us to do so.

Targets were displayed for 1,000 ms in lowercase Arial 36-point typeface. Listeners were tested in sound-attenuated booths. They were instructed to listen to the auditory stimulus and decide as quickly as possible whether the stimulus on the screen was a word or a nonword by pressing one of two appropriately labeled buttons. Five different lists were constructed in which priming condition was counterbalanced across lists. Each participant thus saw each target only once, preceded by one of the five possible primes for that item. Each list also contained all 320 fillers, such that there was an equal number of word and nonword targets preceded by either a word or a nonword prime. Of the total of 480 pairs in a given list, 128 pairs $(27 \%)$ were related (that is, the prime was identical to the target or the prime differed from the target only in the voicing of the first phoneme). There were two randomized versions of each list.

The second part of the experiment consisted of a phoneme identification task. Each participant heard those prevoicing primes that he or she had heard in the priming task ( 24 per lexical status condition). In addition to the voiced primes, they heard the voiceless counterparts of all primes, such that half of the items started with voiced plosives and half with voiceless plosives. In total there were 192 items per listener. Items were presented blocked by place of articulation. Half of the participants started with the labial plosives, and the other half, with the alveolar plosives. They were instructed to label the first sound of each item as $/ \mathrm{b} /$ or $/ \mathrm{p} /$, or as $/ \mathrm{d} /$ or $/ \mathrm{t} /$, by pressing one of two buttons, which were labeled appropriately in each block.

\section{Results}

First we looked at the distribution of correct responses to the targets in the lexical decision phase. Some of the word targets were of low frequency of occurrence. Some of the voiceless word competitors were also of low frequency and might therefore not be regarded as lexical competitors. This could have weakened any possible effect of lexical status. The mean proportion of correct responses was therefore calculated for each of the targets in both Experiment 1 and Experiment 2 (the targets of Experiment 2 were the voiceless counterparts of the targets in Experiment 1). To avoid the influence of any priming effects, only the responses to targets in the unrelated priming condition were considered. All targets for which the proportions of correct responses were more than two standard deviations away from the mean proportion of correct responses (i.e., a cutoff value of $23 \%$ errors) were removed from all subsequent analyses. Targets with voiceless counterparts that were misclassified in more than $23 \%$ of the cases in Experiment 2 were also removed from all further analyses. Nine blue targets, 10 bear targets, 6 blem targets, and 9 brince targets were excluded (in total 34/160 targets; see Appendix). As a result, the mean fre- quency of the words in all conditions increased but was still matched across the blue and brince conditions (39 and 40 per million, respectively) and across the voiced and voiceless word members of the bear condition (16 and 19 per million, respectively).

Identification. For each combination of prevoicing (prevoicing 12, prevoicing 6, and prevoicing 0) and lexical status (blue, bear, blem, and brince), the percentage of voiced responses in the identification phase was calculated separately for each listener. The mean percentages of voiced responses for all listeners are presented in Table 2 . These were close to $100 \%$ in all lexical status conditions for the prevoicing 12 and prevoicing 6 conditions. Items without prevoicing were identified as being voiced less often than those in the two other prevoicing conditions but were still more often identified as being voiced than voiceless. The overall correct identification performance on the voiceless items was $93 \%$.

The proportions of voiced responses were converted through an arcsine transformation (Studebaker, 1985) and submitted to repeated measures analyses of variance (ANOVAs) with the factors prevoicing and lexical status. The main effect of lexical status (higher percentage of voiced responses to words than to nonwords) was significant only in the item analysis, $F_{2}(3,122)=4.72, p<$ .01. There was a main effect of prevoicing in both the participant $\left(F_{1}\right)$ and the item $\left(F_{2}\right)$ analyses, $F_{1}(2,88)=160.99, p<.001$; $F_{2}(2,244)=110.90, p<.001$. Tukey honestly significant difference (HSD) tests showed that in all four lexical status conditions the proportions of voiced responses to items starting with a plosive without prevoicing were significantly smaller than to items starting with plosives with 12 or 6 periods of prevoicing (at the .05 level). Although it seems that this difference was larger in the brince condition than in any of the other lexical status conditions, the interaction between voicing and lexical status was significant only in the item analysis, $F_{2}(6,244)=4.19, p<.001$.

These data show that plosives from which the prevoicing was removed were in general still perceived as being voiced. In the blem condition (which is the most appropriate condition to consider, as there are no lexical factors present in this condition that might have influenced identification), the proportion of voiced responses for the prevoicing 0 condition was almost $85 \%$. As predicted on the basis of van Alphen and Smits's (2004) findings, removing the prevoicing of a voiced plosive reduces the probability of the plosive being judged voiced to some extent, but the other acoustic cues to voicing that are still present provide enough evidence for the plosive usually to be identified as voiced.

Lexical decision. The mean reaction times (RTs), measured from target onset, of the correct responses to targets in each priming condition are plotted separately for each of the four lexical

Table 2

Experiment 1: Percentages of Voiced Responses in the Identification Task

\begin{tabular}{lllll}
\hline & \multicolumn{4}{c}{ Lexical status condition } \\
\cline { 2 - 5 } Priming condition & Blue & Bear & Blem & Brince \\
\hline Prevoicing 12 & 98.7 & 97.9 & 98.9 & 97.1 \\
Prevoicing 6 & 97.3 & 98.1 & 98.3 & 97.9 \\
Prevoicing 0 & 88.3 & 80.2 & 84.6 & 68.1 \\
\hline
\end{tabular}


status conditions in Figures 1 and 2. Figure 1 shows the mean RTs of "yes" responses to word targets, and Figure 2 shows the mean RTs of "no" responses to nonword targets.

We first focus on the conditions with word targets (blue and bear). Figure 1 shows a similar pattern for words without voiceless word competitors and words with voiceless word competitors. Repeated measures ANOVAs on these data showed that there was a significant effect of priming condition (prevoicing 12, prevoicing 6 , prevoicing 0 , voiceless, and unrelated): $F_{1}(4,236)=34.90, p<$ $.001 ; F_{2}(4,236)=22.04, p<.001$, but no effect of competitor (plus or minus lexical competitor) and no interaction. Individual ANOVAs showed that in both lexical status conditions there was a main effect of priming: $F_{1}(4,236)=11.50, p<.001 ; F_{2}(4$, $120)=9.82, p<.001$, in the blue condition, and $F_{1}(4,236)=$ $25.76, p<.001 ; F_{2}(4,116)=12.15, p<.001$, in the bear condition.

For each condition (and also in each of the nonword conditions), $t$ tests on the following five planned comparisons were carried out: prevoicing 12-prevoicing 6, prevoicing 6-unrelated, voicelessunrelated, prevoicing 0 -prevoicing 6 , and prevoicing 0 -voiceless. We corrected for the number of comparisons in each case by applying a modified Bonferroni test (Keppel, 1982, pp. 148-149), which resulted in a rejection probability of .04 (five comparisons between five conditions). The outcomes of the $t$ tests for the five planned comparisons within each lexical status condition are shown in Table 3. Parallel analyses of arcsine transformed error rates were also performed. The mean error proportions are given in Table 4.

These $t$ tests showed the same pattern in both word target conditions. There was no difference in RTs between targets preceded by primes with 12 or 6 periods of prevoicing. Voiced primes with prevoicing showed a clear priming effect: Lexical decisions in these priming conditions were faster than decisions to targets preceded by unrelated primes. The RTs to targets preceded by voiceless primes were as slow as RTs to targets preceded by unrelated primes. This confirms that a minimal phonemic change

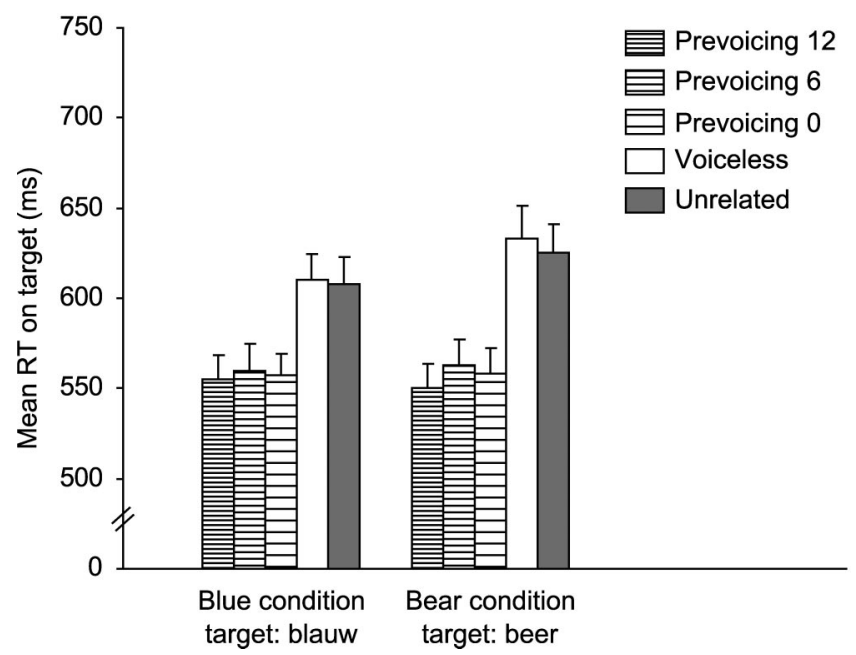

Figure 1. Mean reaction times (RTs) to voiced word targets without voiceless word competitor (the blue condition) and with voiceless word competitor (the bear condition) in each of the five priming conditions in Experiment 1. Error bars indicate standard errors.

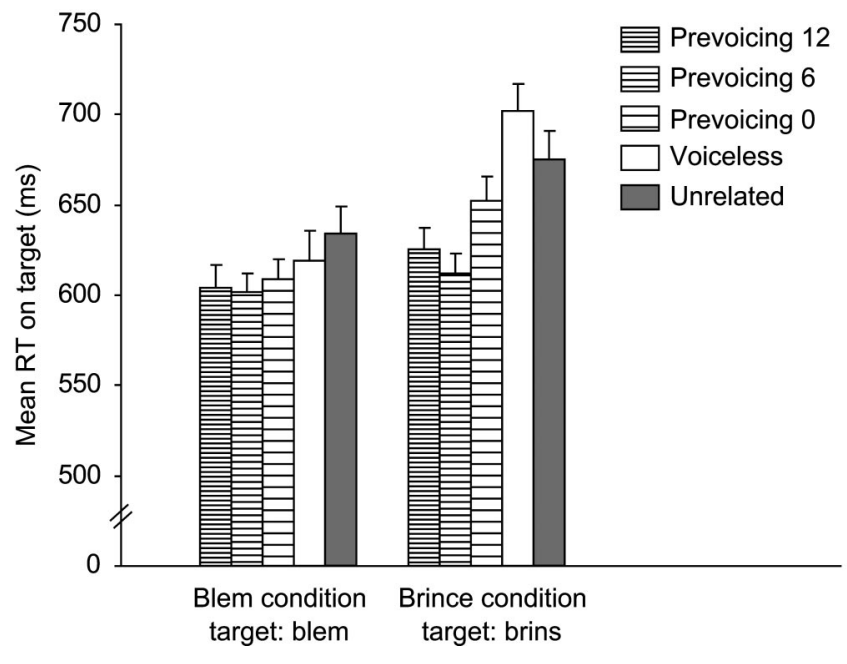

Figure 2. Mean reaction times (RTs) to voiced nonword targets without voiceless word competitor (the blem condition) and with voiceless word competitor (the brince condition) in each of the five priming conditions in Experiment 1. Error bars indicate standard errors.

like a change in voicing is sufficient to make the priming effect disappear. A nonword such as plauw does not prime responses to the word blauw, and a word such as peer does not prime responses to the word beer. Finally, the deletion of prevoicing (prevoicing 0) seems to have no effect on the amount of priming: The words starting with plosives without prevoicing provided the same amount of priming as the same words starting with plosives with prevoicing.

In the analysis of the errors on word targets, there was a main effect of priming, $F_{1}(4,236)=11.12, p<.001 ; F_{2}(4,236)=$ $58.41, p<.001$, but no effect of competitor and no interaction. The two separate ANOVAs, however, showed that the effect of priming condition in the blue condition was significant in the participant analysis, $F_{1}(4,236)=3.49, p<.01$, but not in the item analysis. In the bear condition the effect of priming condition was significant both by participant, $F_{1}(4,236)=8.74, p<.001$, and by item, $F_{2}(4,116)=8.64, p<.001$.

The $t$ tests in the bear condition showed that in contrast to the RTs, there was a significant effect in proportion of errors between prevoicing 12 and prevoicing $6, t_{1}(59)=2.30, p<.04 ; t_{2}(29)=$ $2.72, p<.04$. Although the proportion of errors is small in both conditions, there were significantly more errors in lexical decisions to word targets preceded by identical primes with 6 periods of prevoicing than to targets preceded by primes with 12 periods of prevoicing. In addition to this, there were significantly more errors in lexical decisions to word targets preceded by voiceless primes than to targets preceded by voiced primes without prevoicing, $t(59)=-3.80, p<.001 ; t(29)=-4.01, p<.001$. However, no difference was found between the prevoicing 6 and prevoicing 0 conditions. In this latter respect, the error pattern reflected the RT pattern.

Next, we focus on the conditions with nonword targets (blem and brince; see Figure 2). There was a different pattern between targets without a competitor and those with a competitor: In addition to a significant priming effect, $F_{1}(4,236)=19.12, p<$ $.001 ; F_{2}(4,252)=14.66, p<.001$, there was a main effect of 
Table 3

Experiment 1: $t$ Tests for Planned Comparisons on the Reaction Time Data in the Lexical Decision Task by Comparison and Lexical Status Condition

\begin{tabular}{|c|c|c|c|c|}
\hline \multirow[b]{2}{*}{ Comparison } & \multicolumn{4}{|c|}{ Lexical status condition } \\
\hline & Blue & Bear & Blem & Brince \\
\hline \multirow[t]{2}{*}{ Prevoicing 12 vs. prevoicing 6} & $t_{1}(59)=0.42$ & $t_{1}(59)=1.44$ & $t_{1}(59)=-0.35$ & $t_{1}(59)=-1.22$ \\
\hline & $t_{2}(30)=0.41$ & $t_{2}(29)=0.99$ & $t_{2}(33)=-0.50$ & $t_{2}(30)=-0.99$ \\
\hline \multirow[t]{2}{*}{ Prevoicing 6 vs. unrelated } & $t_{1}(59)=-3.47 * * *$ & $t_{1}(59)=-5.19 * * *$ & $t_{1}(59)=-3.27 * *$ & $t_{1}(59)=-6.33 * * *$ \\
\hline & $t_{2}(30)=-2.97 * *$ & $t_{2}(29)=-3.78 * * *$ & $t_{2}(33)=-2.63^{*}$ & $t_{2}(30)=-4.86^{* * *}$ \\
\hline \multirow[t]{2}{*}{ Unrelated vs. voiceless } & $t_{1}(59)=-0.14$ & $t_{1}(59)=-0.69$ & $t_{1}(59)=1.53$ & $t_{1}(59)=-1.95^{\mathrm{a}}$ \\
\hline & $t_{2}(30)=-0.50$ & $t_{2}(29)=-0.35$ & $t_{2}(33)=1.36$ & $t_{2}(30)=-2.35^{*}$ \\
\hline \multirow[t]{2}{*}{ Prevoicing 0 vs. prevoicing 6} & $t_{1}(59)=-0.29$ & $t_{1}(59)=-0.45$ & $t_{1}(59)=1.07$ & $t_{1}(59)=3.98 * * *$ \\
\hline & $t_{2}(30)=-0.35$ & $t_{2}(29)=-0.35$ & $t_{2}(33)=0.44$ & $t_{2}(30)=3.85^{* * *}$ \\
\hline \multirow[t]{2}{*}{ Prevoicing 0 vs. voiceless } & $t_{1}(59)=-4.35 * * *$ & $t_{1}(59)=-6.52 * * *$ & $t_{1}(59)=-0.99$ & $t_{1}(59)=-4.31 * * *$ \\
\hline & $t_{2}(30)=-5.14 * * *$ & $t_{2}(29)=-4.44 * * *$ & $t_{2}(33)=-0.89$ & $t_{2}(30)=-3.80 * * *$ \\
\hline
\end{tabular}

${ }^{\mathrm{a}} p=.056$

$* p<.04 . \quad * * p<.01 . \quad * * * p<.001$.

competitor, $F_{1}(1,59)=50.56, p<.001 ; F_{2}(1,63)=14.06, p<$ .001 , and a significant interaction between priming condition and competitor, $F_{1}(4,236)=7.38, p<.001 ; F_{2}(4,252)=6.12, p<$ .001 . The main effect of competitor showed that participants were slower in rejecting a nonword when the nonword had a voiceless word competitor than when the nonword did not have a voiceless word competitor. The two separate ANOVAs showed a significant effect of priming condition in both nonword target conditions: $F_{1}(4,236)=3.85, p<.01 ; F_{2}(4,132)=2.53, p<.05$, in the blem condition, and $F_{1}(4,236)=20.26, p<.001 ; F_{2}(4,120)=$ $17.25, p<.001$, in the brince condition.

The $t$ tests (see Table 3 ) showed that in the blem condition the only significant difference was between the prevoicing 6 and unrelated conditions. RTs to targets preceded by primes starting with voiced plosives with prevoicing were faster than RTs to targets preceded by unrelated primes. There was no difference between the RTs to targets preceded by voiceless primes and unrelated primes. This indicates that there was phonological priming from nonword to nonword, but only when the complete string of phonemes of the prime matched the string of graphemes of the target. A nonword such as blem primed responses to the nonword blem, but a nonword such as plem did not prime responses to the nonword blem. The effect of phonological priming on nonwords was rather small in comparison to the effect of identity priming on words.

Table 4

Experiment 1: Percentages of Errors in the Lexical Decision Task

\begin{tabular}{lcccc}
\hline & \multicolumn{4}{c}{ Lexical status condition } \\
\cline { 2 - 5 } Priming condition & Blue & Bear & Blem & Brince \\
\hline Prevoicing 12 & 3.8 & 2.5 & 0.7 & 1.6 \\
Prevoicing 6 & 3.8 & 5.6 & 3.4 & 3.8 \\
Prevoicing 0 & 3.2 & 3.9 & 2.9 & 1.9 \\
Voiceless & 7.8 & 12.2 & 2.2 & 5.4 \\
Unrelated & 3.8 & 8.1 & 3.4 & 4.0 \\
\hline
\end{tabular}

Phonological priming was also present in the brince condition: The nonword targets were primed by nonword primes starting with prevoicing, and there was no difference between prevoicing 6 and prevoicing 12. This time, however, primes starting with voiceless plosives showed an inhibitory effect: Listeners were slower in deciding that brins, for example, was not a word when they had just heard the word prins than when the target was preceded by an unrelated nonword. This difference was significant by items but not by participants $(p=.056)$. As predicted, the decision that a string of graphemes did not form a word was slowed down somewhat by the activation of a word that was very similar to the nonword.

The most interesting condition is the prevoicing 0 condition. The results show that in the brince condition there was a difference between voiced primes with and without prevoicing. When a nonword target was preceded by a prime starting with a voiced plosive with prevoicing, participants were faster in rejecting the target as a word than when the target was preceded by a prime starting with a voiced plosive without prevoicing. This suggests that nonwords without prevoicing such as brins had significantly activated their matched words (e.g., prins). However, RTs to targets preceded by prevoicing 0 primes were still faster than RTs to targets preceded by voiceless primes, indicating, for example, that brins without prevoicing had activated the word prins to a lesser extent than prins itself had.

The analysis of the errors on nonword targets showed a main effect of priming, $F_{1}(4,236)=3.10, p<.05 ; F_{2}(4,252)=3.54$, $p<.01$, but no effect of competitor and no interaction. In the separate ANOVAs there was no effect of priming in the blem condition, but there was in the brince condition, $F_{1}(4,236)=2.69$, $p<.05 ; F_{2}(4,120)=3.63, p<.01$.

The $t$ tests showed that in the brince condition the only significant difference in error rates was between targets preceded by voiceless primes and targets preceded by voiced primes without prevoicing, $t_{1}(59)=-2.35, p<.04 ; t_{2}(30)=-2.76, p<.01$. In line with the RT pattern, participants made more errors in rejecting, for example, brins as a nonword after they had heard prins than after brins without prevoicing. There was, however, no sig- 
nificant difference in errors between targets preceded by the prevoicing 6 and prevoicing 0 primes.

\section{Discussion}

Lexical decisions were facilitated by primes that were identical to the targets in comparison to primes that were unrelated. Furthermore, when the first phoneme of the prime differed from the target only in the voicing of the initial plosive, there was no priming effect. In addition, the decision that a nonword target was not a word tended to be slowed down when a voiceless word competitor could have been activated by the prime.

We also observed limited effects of prevoicing variation. There were no differences in lexical decision latencies to targets preceded by primes with 12 versus 6 periods of prevoicing in any of the lexical status conditions. Only in one condition was there a difference in the proportion of errors between these two prevoicing conditions. Overall, the difference between 12 and 6 periods of prevoicing before the burst of voiced plosives did not reliably affect the activation of the lexical candidates starting with these plosives. Likewise, the same quantitative difference between 6 periods of prevoicing and no prevoicing did not affect lexical decisions to voiced word targets (i.e., in the blue and bear conditions).

It is interesting to note, however, that there was a difference in RTs between the prevoicing 6 and prevoicing 0 conditions in the brince condition. When a visual nonword target such as brins, which has a voiceless word competitor, was preceded by brins without prevoicing, lexical decisions on this target were significantly slower than when it was preceded by brins with 6 periods of prevoicing. This suggests that the prime had substantially activated the voiceless word competitor (e.g., prins), making it harder to reject the visual nonword target as a word. In the blue and blem conditions there were no voiceless word competitors to be activated. This may be why there was no effect of prevoicing deletion in these conditions (i.e., in the absence of a voiceless lexical competitor, there is no interference in lexical decisions to the voiced target)

In both the brince and bear conditions, however, there were voiceless competitors that could have been activated, but the difference between priming conditions with and without prevoicing was found only in the brince condition. The crucial difference between these two conditions is that in the former, only the voiceless counterpart was a word (e.g., prins, prince), whereas in the latter, both the voiced and the voiceless counterparts were competing words (e.g., beer, bear and peer, pear). The identification data suggest that items starting with voiced plosives without prevoicing activate both voiced and voiceless word candidates but that candidates starting with voiced plosives receive more activation than candidates starting with voiceless plosives, because the plosives without prevoicing are more often judged to be voiced than voiceless. This implies that in the brince condition the unprevoiced primes activated the voiceless word candidates to some extent. This small amount of activation was not suppressed by other lexical candidates, as there were no voiced word candidates, and so lexical decisions to the nonword targets were slowed. In the bear condition, however, both the voiced and the voiceless word candidates were activated and would compete for recognition. On the basis of the identification data, one would expect that the voiced word candidate would win the competition.

One possible explanation for these findings in the bear condition, therefore, is that the lexical representation of the voiced word candidate was activated so strongly in comparison to that of the voiceless word candidate that, at the moment of the lexical decision on the target, the voiced candidate had already suppressed the activation of the voiceless word candidate completely, as if the voiceless candidate had never been activated. An alternative explanation bears on the fact that listeners were asked to make lexical decisions on visual targets. We can describe this explanation best in the context of a model with two connected representations: an orthographic lexical representation and a phonological lexical representation. According to this model, participants made their decisions on the visual targets on the basis of the degree of activation of orthographic lexical representations. These representations would receive most of their activation from the target and only some activation from phonological representations that are activated by the primes. It is therefore possible that the activation of the phonological voiceless word representation given a bear prime without prevoicing had not been suppressed completely by the more strongly activated representation of the voiced competitor, but that this activation could not be measured in visual lexical decisions. After all, the visual target unambiguously started with a grapheme corresponding to a voiced consonant. Thus, there was clear evidence from the visual modality that the target was voiced. (Remember that we use the terms voiced and voiceless in relation to the visual target to refer to the voicing of the phoneme that corresponds to the initial grapheme.) Furthermore, if the prime without prevoicing activates both voiced and voiceless word candidates, the orthographic lexical representation would also receive activation from the phonological representation of the voiced lexical candidate. So the orthographic voiced representation would have more visual support and more support from the auditory system than the orthographic voiceless representation. In other words, there would be little conflict between the auditory and visual modalities. Lexical competition in the visual wordrecognition system could thus allow the voiced candidate to win, suppressing any activation of the orthographic representation of the voiceless candidate. The voiceless word candidate, though its phonological representation was activated, would then not influence the visual lexical decision on the voiced target.

If the absence of a clear conflict between phonological and orthographic information is indeed the explanation for the pattern of results in Experiment 1, the use of the voiceless word candidate as the visual target rather than the voiced word candidate should allow the weakly activated phonological word representation of the voiceless word candidate to influence target lexical decisions. We should then find faster lexical decisions to voiceless targets when they are preceded by voiced primes without prevoicing than when they are preceded by primes with prevoicing. If the first explanation is correct, however, and the activation of the voiceless word candidate in the auditory system is already completely suppressed by the more strongly activated voiced word candidate, then there should be no difference in lexical decisions to voiceless word targets preceded by voiced word primes without prevoicing and 
voiced word primes with prevoicing. Experiment 2 was designed to test these two alternative explanations. ${ }^{2}$

\section{Experiment 2}

In this experiment, participants heard the same primes as in Experiment 1, but this time the targets were the voiceless members of each pair of stimuli (see Table 1). We expected to find the same general patterns as were found in Experiment 1. However, these patterns were now expected to appear in different conditions from those in Experiment 1. First, the identity priming effect for both word and nonword targets was now expected to appear when the targets were preceded by voiceless primes. Second, when targets were preceded by clearly voiced primes, no priming effect was expected. Third, when the target was a nonword and the prime was a word that differed from the target only in initial voicing, an inhibitory effect was expected. In Experiment 2, this would be the case in the blue condition, when a voiceless nonword target such as plauw was preceded by a voiced word prime such as blauw.

We expected to find no substantial difference between the lexical decisions to targets preceded by the two types of primes with prevoicing (12 vs. 6 periods) in any of the four lexical status conditions. Furthermore, we did not expect to find differences between the condition with voiced primes without prevoicing and voiced primes with prevoicing (prevoicing 6 and prevoicing 0 ) in the lexical status conditions in which the voiceless members were nonwords (i.e., in the blem and blue conditions). The results of Experiment 1 suggest that the deletion of prevoicing does not substantially affect activation of lexical candidates starting with voiced plosives if there are no voiceless word candidates to be activated that could enter the competition process. However, when the voiceless members did form words (i.e., in the brince and bear conditions), we expected to see a difference between primes with prevoicing and those without, as the latter should activate the voiceless word candidates more strongly. In the brince condition the voiceless word candidate was the only candidate, and therefore the primes without prevoicing were expected to facilitate lexical decisions on the voiceless targets.

The crucial condition was the bear condition. We have already proposed two possible explanations for the failure in Experiment 1 to find a difference in this condition between the prevoicing 6 and prevoicing 0 conditions. If the more strongly activated voiced candidate immediately suppresses the activation of the voiceless candidate completely (i.e., as if it never had been activated), we should again find no difference between these two conditions. In contrast, if it is the case that the lack of difference between these two conditions in Experiment 1 was due to the absence of a strong conflict between visual and phonological information, we should expect that the activation of the phonological word representation of the voiceless candidate would be able to influence the activation of the orthographic representation of the voiceless word target. We would then expect that lexical decisions on voiceless word targets in the bear condition would be faster when targets were preceded by primes without prevoicing than when they were preceded by primes with prevoicing.

\section{Method}

Participants. Sixty native Dutch speakers from the MPI participant pool were paid to take part. None reported any hearing loss, and none had participated in Experiment 1.

Materials and procedure. The materials were identical to those used in Experiment 1, except that the visual targets were the voiceless members of each stimulus pair. This resulted in a change in the lexical status of the targets in the brince and blue conditions. As a result, the lexical status of the unrelated primes was not identical to the lexical status of the related voiced primes in these conditions. Table 1 shows the complete design of Experiment 2, with examples. The procedure was identical to that for the lexical-decision task in Experiment 1. There was, however, no phoneme identification task.

\section{Results}

The mean RTs of the correct responses to targets in each priming condition are plotted separately for each of the four lexical status conditions in Figures 3 and 4. Note that this time the division based on correct "yes" and "no" responses resulted in different combinations of lexical status conditions than in Experiment 1: "Yes" responses were now correct in the brince and bear conditions (see Figure 3), and "no" responses were now correct in the blem and blue conditions (see Figure 4). The analyses of the RTs and the errors were identical to those carried out in Experiment 1. The outcomes of all separate $t$ tests on the RTs are shown in Table 5 , and the mean percentages of errors are shown in Table 6 .

The ANOVAs on both the brince and bear conditions showed that there was a significant effect of priming condition: $F_{1}(4$, $236)=18.21, p<.001 ; F_{2}(4,236)=20.55, p<.001$, but no significant effect of competitor. The interaction between priming condition and competitor was significant in the participant analysis, $F_{1}(4,236)=17.67, p<.001$, but not in the item analysis. Individual ANOVAs showed that the effect of priming condition was significant in both lexical status conditions: $F_{1}(4,236)=$ $16.97, p<.001 ; F_{2}(4,120)=11.05, p<.001$, in the brince condition, and $F_{1}(4,236)=16.67, p<.001 ; F_{2}(4,116)=10.75$, $p<.001$, in the bear condition.

In the brince condition, as in all four conditions in Experiment 1 , there was no difference between RTs to targets preceded by primes with 6 periods of prevoicing and those preceded by primes with 12 periods of prevoicing. The RTs in these two voiced priming conditions were not different from RTs in the unrelated conditions. This indicates that responses to the word target prins, for example, were not facilitated by the presentation of the nonword prime brins. As in Experiment 1, lexical decisions to word targets were not facilitated by primes that were identical to the targets except for the voicing of the initial plosive. The voiceless

\footnotetext{
${ }^{2}$ We acknowledge that there are several possible accounts of how listeners make lexical decisions in the cross-modal identity-priming task Such accounts can differ with respect to the number and nature of lexical and prelexical representations involved, the connections among these representations, and the assumptions that are made about the mechanism(s) underlying lexical decisions. Our experiments were not designed to distinguish among such accounts. The use of separate phonological and orthographic lexical representations in the current proposal is primarily for expository purposes. It offers a straightforward framework in which to describe the complex interactions of lexical status, modality of presentation, and VOT variation that were observed.
} 


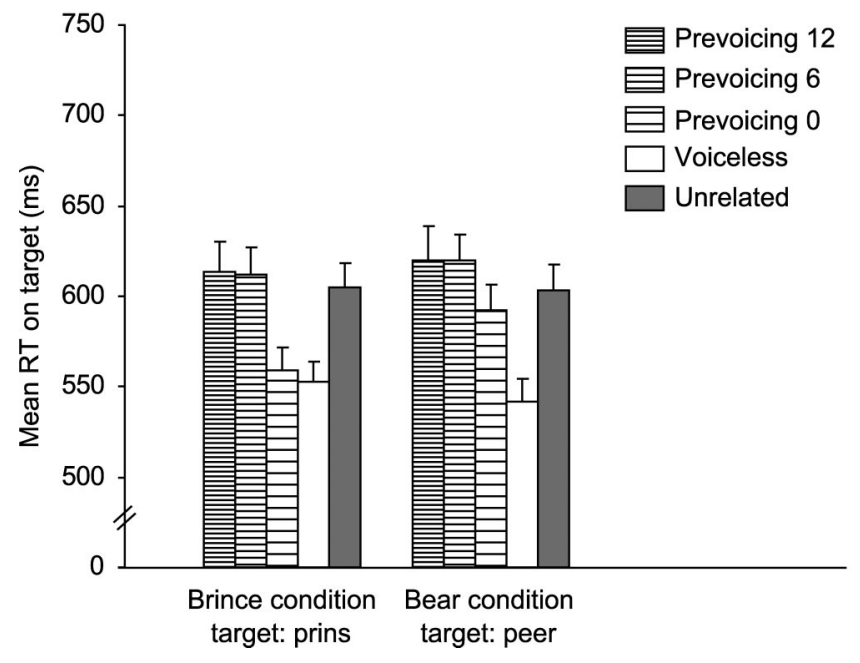

Figure 3. Mean reaction times (RTs) to voiceless word targets without voiced word competitor (the brince condition) and with voiced word competitor (the bear condition) in each of the five priming conditions in Experiment 2. Error bars indicate standard errors.

primes showed, however, a clear priming effect: Participants were faster in deciding that the target was a word when prime and target were identical. There was no difference in RTs between responses to targets preceded by primes without prevoicing (prevoicing 0) and voiceless primes. This indicates that nonwords such as brins without prevoicing had activated their matched words (e.g., prins). Responses to targets preceded by these primes were faster than those to targets preceded by voiced primes.

As shown in Figure 3 and Table 5, the pattern in the bear condition is similar to that in the brince condition, except for the effect of voiced primes without prevoicing. There was again no difference between the 12-period and 6-period conditions, and there was no difference in RTs between responses to the voiceless word targets preceded by these voiced primes and unrelated primes. Again, the voiceless prime showed a clear priming effect: RTs were faster to targets preceded by voiceless primes than to those preceded by unrelated primes. In contrast to the brince condition, however, responses to targets preceded by 0 -period primes were slower than responses to targets preceded by voiceless primes, but faster to targets preceded by voiced primes. Prevoicing 0 was thus an intermediate case between unambiguously voiced and voiceless primes.

The analysis of the errors on word targets showed that there was a main effect of priming condition, $F_{1}(4,236)=17.33, p<.001$; $F_{2}(4,236)=16.68, p<.001$. There was no effect of competitor, and the interaction between priming condition and competitor was significant only in the participant analysis, $F_{1}(4,236)=4.50, p<$ .01 . The two individual ANOVAs showed that in both the brince and the bear conditions there was a significant effect of priming condition, $F_{1}(4,236)=7.88, p<.001 ; F_{2}(4,120)=8.74, p<$ .001 , in the brince condition, and $F_{1}(4,236)=11.07, p<.001$; $F_{2}(4,116)=8.80, p<.001$, in the bear condition.

The $t$ tests showed that in the brince condition the proportion of errors was lower when the voiceless targets were preceded by voiceless primes than when preceded by unrelated primes, $t_{1}(59)=2.80, p<.01 ; t_{2}(30)=3.52, p<.001$. The priming effect in RTs of primes that were identical to the targets was therefore also reflected in the error pattern. In addition to this, there were fewer errors when the target was preceded by a voiced prime without prevoicing than when it was preceded by a voiced prime with prevoicing, $t_{1}(59)=-3.38, p<.001 ; t_{2}(30)=-4.47, p<$ .001. This finding is also in line with the RT pattern.

In the bear condition, there were more errors when the voiceless word target was preceded by a voiced word prime than when it was preceded by an unrelated prime, $t_{1}(59)=4.04, p<.001 ; t_{2}(29)=$ $3.20, p<.01$. This reflects the difference in RTs that was found between prevoicing 6 and unrelated primes. In contrast to the RT pattern, which showed that prevoicing 0 was an intermediate case between voiced and voiceless primes, the error pattern showed that there were fewer errors in the prevoicing 0 than in the prevoicing 6 condition, $t_{1}(59)=-3.51, p<.001 ; t_{2}(29)=-3.00, p<.01$, but no difference between the prevoicing 0 and voiceless conditions.

The results in the blem and blue conditions are summarized in Figure 4 and Tables 5 and 6 . The combined ANOVAs on these conditions showed a significant main effect of priming, $F_{1}(4$, $236)=31.38, p<.001 ; F_{2}(252)=5.92, p<.001$, a significant main effect of competitor, $F_{1}(1,59)=6.49, p<.05 ; F_{2}(1,63)=$ $19.63, p<.001$, and a significant interaction between priming and competitor, $F_{1}(4,236)=16.22, p<.001 ; F_{2}(4,252)=4.82, p<$ .001 . The two separate ANOVAs showed that in the blem condition the effect of priming condition was significant only in the participant analysis, $F_{1}(4,236)=4.87, p<.001$. In the blue condition the effect was significant in both analyses, $F_{1}(4,236)=$ $11.69, p<.001 ; F_{2}(4,120)=7.93, p<.001$.

The outcomes of the $t$ tests showed that in the blem condition only one of the comparisons was significant. Responses to targets preceded by voiceless primes were significantly faster than responses to targets preceded by unrelated primes. There was no significant difference between the prevoicing 0 and voiceless conditions.

In the blue condition there was again no difference between the 6- and 12-period conditions. Furthermore, responses to voiceless

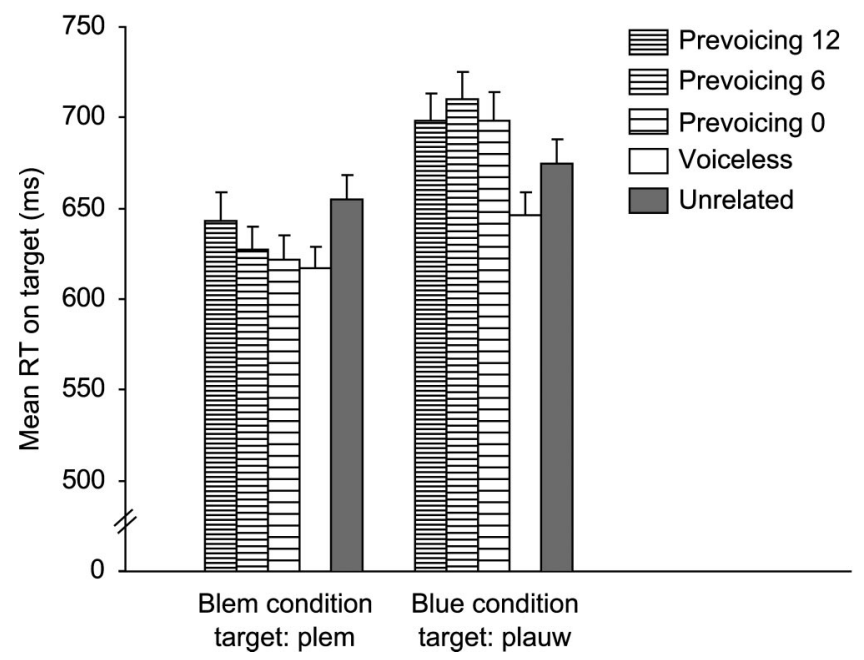

Figure 4. Mean reaction times (RTs) to voiceless nonword targets without voiced word competitor (the blem condition) and with voiced word competitor (the blue condition) in each of the five priming conditions in Experiment 2. Error bars indicate standard errors. 
Table 5

Experiment 2: $t$ Tests for Planned Comparisons on the Reaction Time Data in the Lexical Decision Task by Comparison and Lexical Status Condition

\begin{tabular}{|c|c|c|c|c|}
\hline \multirow[b]{2}{*}{ Comparison } & \multicolumn{4}{|c|}{ Lexical status condition } \\
\hline & Blue & Bear & Blem & Brince \\
\hline \multirow[t]{2}{*}{ Prevoicing 12 vs. prevoicing 6} & $t_{1}(59)=1.05$ & $t_{1}(59)=-0.00$ & $t_{1}(59)=-1.43$ & $t_{1}(59)=-0.17$ \\
\hline & $t_{2}(30)=1.34$ & $t_{2}(29)=0.28$ & $t_{2}(33)=-1.35$ & $t_{2}(30)=0.11$ \\
\hline \multirow[t]{2}{*}{ Prevoicing 6 vs. unrelated } & $t_{1}(59)=3.03 * *$ & $t_{1}(59)=1.70$ & $t_{1}(59)=-2.49 *$ & $t_{1}(59)=0.85$ \\
\hline & $t_{2}(30)=2.57 *$ & $t_{2}(29)=1.88$ & $t_{2}(33)=-1.63$ & $t_{2}(30)=0.81$ \\
\hline \multirow[t]{2}{*}{ Unrelated vs. voiceless } & $t_{1}(59)=3.12 * *$ & $t_{1}(59)=6.99 * * *$ & $t_{1}(59)=4.51 * * *$ & $t_{1}(59)=4.57 * * *$ \\
\hline & $t_{2}(30)=3.15 * *$ & $t_{2}(29)=4.70 * * *$ & $t_{2}(33)=2.20 *$ & $t_{2}(30)=4.52 * * *$ \\
\hline \multirow[t]{2}{*}{ Prevoicing 0 vs. prevoicing 6} & $t_{1}(59)=-1.06$ & $t_{1}(59)=-2.36^{*}$ & $t_{1}(59)=-0.71$ & $t_{1}(59)=-6.23 * * *$ \\
\hline & $t_{2}(30)=-0.85$ & $t_{2}(29)=-2.32 *$ & $t_{2}(33)=-0.28$ & $t_{2}(30)=-5.35 * * *$ \\
\hline \multirow[t]{2}{*}{ Prevoicing 0 vs. voiceless } & $t_{1}(59)=6.73 * * *$ & $t_{1}(59)=5.20 * * *$ & $t_{1}(59)=0.53$ & $t_{1}(59)=0.67$ \\
\hline & $t_{2}(30)=3.54 * * *$ & $t_{2}(29)=3.71 * * *$ & $t_{2}(33)=0.39$ & $t_{2}(30)=0.84$ \\
\hline
\end{tabular}

$* p<.04 . \quad * * p<.01 . \quad * * * p<.001$.

nonword targets preceded by voiced word targets were slower than responses to these targets preceded by unrelated primes. This indicates that lexical decisions to nonword targets such as plauw were inhibited by word primes such as blauw in comparison to unrelated word primes. As before, there was a clear priming effect of the voiceless primes: RTs were faster when targets were preceded by voiceless primes than when they were preceded by unrelated primes. The 0 -period voiced primes behaved like the other voiced primes: There was no difference between 0 - and 6-period primes, and RTs to targets preceded by 0-period primes were significantly slower than those to targets preceded by voiceless primes.

There were no significant effects in the error analyses on nonword targets.

\section{Discussion}

Experiment 2 showed the same general patterns as Experiment 1. First, all priming conditions in which primes were identical to targets showed facilitation in lexical decisions. In Experiment 1 this effect appeared in all clearly voiced priming conditions (prevoicing 6 and prevoicing 12), and in Experiment 2, in all voiceless priming conditions. Second, identity priming occurred only when the prime was identical to the target. If the prime differed from the target only in the voicing of the initial plosive, the facilitation disappeared. This effect went both ways: Responses to targets starting with voiced plosives were not facilitated by the voiceless

Table 6

Experiment 2: Percentages of Errors in the Lexical Decision Task

\begin{tabular}{lcccc}
\hline & \multicolumn{4}{c}{ Lexical status condition } \\
\cline { 2 - 5 } Priming condition & Blue & Bear & Blem & Brince \\
\hline Prevoicing 12 & 5.7 & 12.0 & 2.5 & 8.4 \\
Prevoicing 6 & 4.9 & 13.6 & 2.5 & 7.8 \\
Prevoicing 0 & 4.5 & 5.8 & 3.7 & 3.2 \\
Voiceless & 4.3 & 3.3 & 3.2 & 1.6 \\
Unrelated & 5.1 & 4.7 & 3.7 & 5.1 \\
\hline
\end{tabular}

counterparts of the targets (the voiceless priming conditions in Experiment 1), and responses to targets starting with voiceless plosives were not facilitated by the voiced counterparts (the clearly voiced priming conditions in Experiment 2). Third, making a nonword decision was harder when the nonword target was preceded by a prime with the opposite voicing, but only when the prime was a word (the voiceless priming condition in the brince condition of Experiment 1 and the voiced priming conditions in the blue condition of Experiment 2).

As in Experiment 1, there were no differences in Experiment 2 in RTs between the priming conditions with 6 and 12 periods of prevoicing. Both of these types of prevoicing variation appear to provide approximately the same degree of evidence that the plosive is voiced and hence to activate lexical candidates to a similar degree. In addition, there was again no difference between voiced primes with and without prevoicing when the voiceless members of the pairs were nonwords. This indicates that voiced primes without prevoicing contain sufficient acoustic support for the primes to be considered to begin with voiced plosives. In some of the conditions in which the voiceless members were words, however, the presentation of primes without prevoicing resulted in different RTs in comparison to primes with prevoicing. This suggests that primes without prevoicing also substantially activate voiceless word candidates. Whether the activated voiceless word candidate can affect the speed of the lexical decision on the target in a graded way seems to depend on the presence or absence of a conflict between auditory and visual information.

In the bear condition, when the voiced target was a word (e.g., beer) with a voiceless word competitor (e.g., peer), there was no difference between the effects of primes with prevoicing and the effects of voiced primes without prevoicing (Experiment 1). But when the targets started with a voiceless plosive, there was a difference (Experiment 2). We suggest that voiced primes without prevoicing activate both voiced and voiceless word candidates, but the former more strongly. Thus, when a listener hears beer without prevoicing, the phonological representations of both beer and peer will be differentially activated and will spread different amounts of activation to those words' orthographic representations. When the target is voiced, the visual input will result in strong activation of the orthographic representation of beer. This representation thus 
receives strong evidence from both vision and audition, whereas the orthographic representation of peer is activated only weakly via the auditory input. In other words, there is little conflict between the two modalities. We assume that the activation of the orthographic representation of peer is too weak to compete seriously with that of beer under these circumstances and therefore does not influence the lexical decision on the target. But when the target is voiceless, the orthographic representation of peer will receive strong activation as a result of the visual input and some extra activation via the weakly activated phonological representation of peer. The orthographic representation of beer will also be activated via the activated phonological representation of beer and will compete with the orthographic representation of peer. In this case there is thus stronger conflict. The activation resulting from the auditory prime without prevoicing contributes to the competition between beer and peer. This extra activation provided by the voiced prime without prevoicing results in faster decisions to peer than when the prime is clearly voiced.

These claims are supported by the findings in the brince conditions. Here, only the voiceless lexical candidate (e.g., prins) could be activated (brins is a nonword). When the target was voiced and thus a nonword, the voiced prime without prevoicing resulted in slower "no" decisions to the nonword target than when the prime was prevoiced, and decisions were even slower when the prime was voiceless (Experiment 1). When the target was voiceless and thus a word, however, both the voiced prime without prevoicing and the voiceless prime resulted in faster decisions in comparison to the prevoiced primes (Experiment 2). The voiced prime without prevoicing can now activate only the voiceless word candidate prins, as there is no voiced lexical candidate. If we assume that the phonological representation of prins will be activated more strongly for a listener upon hearing a voiceless prime than upon hearing a voiced prime without prevoicing, more activation will spread to the orthographic representation of prins in the former case than in the latter. The activation of the orthographic representation of the word prins slows down the decision that brins is a nonword: There were slower responses to brins after voiceless primes than after voiced primes without prevoicing.

This difference in activation of the phonological representation of the voiceless lexical candidate was, however, not detected when the target was voiceless. Under these conditions, the visual input will strongly activate the orthographic representation of voiceless words such as prins. The extra activation that this representation receives from the spoken input when the prime is voiceless or voiced without prevoicing speeds up lexical decisions. But because there is little conflict between visual and auditory information about the lexical status of the target, both primes result in the same degree of facilitation.

In summary, Experiments 1 and 2 show that variation in prevoicing affects the activation of phonological representations of words. There was no significant effect on RTs of the duration of prevoicing. Both tokens with 6 and those with 12 periods of prevoicing were clear voiced plosives, and items starting with these plosives activated word candidates starting with voiced plosives equally strongly. There was no evidence that primes with 6 periods of prevoicing activated words starting with voiceless plosives. Voiced primes without prevoicing, however, showed a different pattern. Removing the prevoicing of voiced plosives took away an important cue for the voicing of that plosive, but the remaining cues provided sufficient evidence for the plosive to support lexical candidates starting with voiced plosives. Nevertheless, items starting with these plosives without prevoicing also partly activated word candidates starting with voiceless plosives.

It is important to note that even though the results suggest that under some conditions it is difficult to pick up differences in lexical activation using the cross-modal identity-priming task, the crucial finding is that the results do show a difference between the two types of prevoicing variation. It may be the case that the difference in the amount of prevoicing ( 12 vs. 6 periods) does affect lexical access but that this difference is too small to be detected consistently in this paradigm (though note that we did detect one such difference in error rates in the blue condition in Experiment 1). Critically, however, lexical decisions were reliably influenced by the presence versus absence of prevoicing. We can therefore conclude that removal of prevoicing has a stronger effect on lexical access in Dutch than a change in the amount of prevoicing.

Another point of concern is the moment at which the target was presented in relation to the prime. Recall that targets were presented $200 \mathrm{~ms}$ after the onset of the burst of the initial plosive of the prime. As a result, the time interval between the beginning of the prime and the beginning of the target differed across conditions, with longest intervals for the primes with 12 periods of prevoicing and smallest intervals for primes without prevoicing. Given the fact that variation in prevoicing necessarily involves a durational difference, it is impossible to control for this factor across prevoicing conditions. However, by presenting the target $200 \mathrm{~ms}$ after the onset of the burst, we at least ensured that listeners had always heard all information that was necessary to identify the first consonant. Still, one could argue that the difference in the degree of priming between primes with 6 periods of prevoicing and primes with no prevoicing is due to the fact that lexical activation had more time to evolve in the case of primes with 6 periods of prevoicing. If this argument were correct, we should have found a clear stepwise pattern across the three prevoicing conditions (with more prevoicing resulting in faster RTs in Experiment 1 and in slower RTs in Experiment 2). This was not the case, however. It is therefore unlikely that the patterns we found are a result of this timing difference. Unfortunately, however, primetarget timing differences are a necessary consequence of any durational difference among primes and therefore remain a possible artifact when durational differences are investigated using priming tasks.

The results so far show that the same quantitative difference in prevoicing of 12 versus 6 periods of prevoicing and of 6 versus 0 periods of prevoicing has qualitatively different effects on lexical access. This difference is in line with the fact that although all three prevoicing durations fall within the natural range of prevoicing variation, plosives with prevoicing are unambiguously voiced whereas plosives without prevoicing are not. The absence of a difference in the identification and priming tasks between the two conditions with prevoicing, however, could also be due to a lack of perceptual sensitivity - that is, listeners may be unable to hear the difference between 12 and 6 periods of prevoicing. Experiment 3 was therefore designed to test the ability of listeners to discriminate among the three different durations of prevoicing. In addition, our aim was to show that the effects of prevoicing variation on 
lexical access found in the two priming experiments would also appear in a different experimental paradigm.

\section{Experiment 3}

In this experiment listeners were asked to indicate whether two auditory items were the same or different. The voiced primes from Experiments 1 and 2 were used. The two items either were identical or differed only in the duration of prevoicing of the initial voiced plosive. We predicted that listeners would be able to discriminate between items with and without prevoicing (prevoicing 12 vs. prevoicing 0 and prevoicing 6 vs. prevoicing 0 ). The crucial question was whether listeners could also discriminate between items with two different durations of prevoicing (prevoicing 12 vs. prevoicing 6). One would expect that it is easier to detect the difference between the absence and presence of a particular acoustic event (prevoicing) than to detect the difference between the same acoustic events that differ only in duration. We therefore predicted that it would be harder to discriminate between the prevoicing 12 and prevoicing 6 stimuli than between either of the other two pairs.

We also expected that the different activation patterns of lexical candidates across conditions would play a role in the discrimination task. Although listeners were instructed to focus on small acoustic differences between the two stimuli, we assumed that they would make use of any information that might help them to perform the task, including lexical information. We therefore predicted, on the basis of the preceding experiments, that the presence of a voiceless word candidate would facilitate the discrimination between items with and without prevoicing.

\section{Method}

Participants. A further 12 native speakers of Dutch from the MPI participant pool were paid for taking part. None reported any hearing loss.

Materials. The materials consisted of the 160 voiced primes from Experiments 1 and 2. Six pairs were constructed per item, so that all combinations of prevoicing appeared: $12-12$ periods, $6-6$ periods, and $0-0$ periods (the "same" pairs); and $12-0$ periods, $6-0$ periods, and $12-6$ periods (the "different" pairs). Order of prevoicing conditions was counterbalanced, such that half of the pairs were presented in one order (e.g., longer prevoicing first) and the other half in the reversed order. In total there were 960 pairs.

Procedure. The two members of each pair were separated by an ISI of $300 \mathrm{~ms}$. The intertrial interval was $1,500 \mathrm{~ms}$. Participants were asked to listen carefully, especially to the very beginning of each stimulus, and then indicate, by pressing one of two appropriately labeled buttons, whether the two stimuli sounded exactly the same or were different. Before the experiment started, listeners heard 12 "different" pairs and were told beforehand that they consisted of items that had slightly different onsets. The familiarization phase was followed by a practice phase with 24 trials. Participants then heard all 960 pairs in random order. There were four different randomized versions, each heard by three listeners.

\section{Results}

First, following Macmillan and Creelman (1991), mean $d^{\prime}$ values for each type of "different" pair were calculated for each subject. The mean $d^{\prime}$ values for the three combinations were as follows: 12 versus 0 periods: $3.42 ; 6$ versus 0 periods: $2.53 ; 12$ versus 6 periods: 1.40 . There was a significant difference among these three combinations: $F_{1}(2,22)=32.43, p<.001 ; F_{2}(2$, $250)=170.14, p<.001$. Tukey's HSD tests showed that all pairwise differences between pairs were significant. Participants found it easiest to discriminate 0 and 12 periods of prevoicing, whereas discrimination of 0 and 6 periods was more difficult, and the difference between 12 and 6 periods was the hardest to detect. All $d^{\prime}$ values differed significantly from zero: $12-0$ periods, $t_{1}(11)=12.23, p<.001 ; t_{2}(125)=39.89, p<.001 ; 6-0$ periods, $t_{1}(11)=11.82, p<.001 ; t_{2}(125)=30.05, p<.001 ; 12-6$ periods, $t_{1}(11)=5.92, p<.001 ; t_{2}(125)=19.72, p<.001$. This indicates that listeners performed above chance on all three types of pair.

The influence of the lexical status of both the voiced item and the voiceless counterpart (whether there was a voiceless word competitor or not) was then explored. The proportion of correct responses was calculated for each listener as a function of prevoicing pair and lexical status condition (blue, bear, brince, and blem). The mean proportions of correct responses, pooled across participants, are shown in Figure 5 ("same" pairs) and Figure 6 ("different" pairs). ${ }^{3}$

The mean proportions of correct responses for each combination of lexical status and prevoicing pair were converted through an arcsine transformation (Studebaker, 1985) for each participant. Subject and item three-way repeated measures ANOVAs were performed on these values, with prevoicing pair, lexical status of the voiced items, and lexical status of the voiceless counterparts as factors. The "same" and "different" pairs were analyzed separately.

In the "same" pairs there was only a main effect of prevoicing pair, $F_{1}(2,22)=7.87, p<.01 ; F_{2}(2,244)=76.29, p<.001$. A post hoc Tukey's HSD test showed that the proportion of correct responses was smaller for $0-0$ period pairs than for $6-6$ or $12-12$ period pairs in both the subject and item analyses, presumably because the members of the $0-0$ pairs were ambiguous (voiced or voiceless), whereas the $12-12$ and 6-6 pairs were not. There was no difference between the pairs with prevoicing and no effects of lexical status.

In contrast, in the "different" pairs, there was a main effect of both prevoicing pair, $F_{1}(2,22)=40.43, p<.001 ; F_{2}(2,244)=$ $309.67, p<.001$, and lexical status of the voiceless counterpart, $F_{1}(1,11)=29.72, p<.001 ; F_{2}(1,122)=21.51, p<.001$. In addition to these two main effects, there was a significant interaction between those two factors: $F_{1}(2,22)=7.91, p<.01 ; F_{2}(2$, $244)=4.57, p<.05$. No other main effects or interactions were significant. A post hoc Tukey's HSD test showed that all overall pairwise differences between the three pairs were significant at the .05 level (i.e., percentage correct performance was ranked as follows: $12-0$ periods $>6-0$ periods $>12-6$ periods). This pattern confirms what was observed in the $d^{\prime}$ analysis. A Tukey's

\footnotetext{
${ }^{3}$ These proportions do not accurately inform us about the accuracy of listeners' performance, because for this purpose both the proportion of hits and the proportion of false alarms should be taken into account (as in the $d^{\prime}$ analysis). Listeners had a strong bias to respond "same" (the proportion of false alarms to the "same" pairs was very low). If listeners were not able to hear the difference between 12 and 6 periods of prevoicing, they would thus have responded "same" to almost all of these pairs, resulting in a proportion of correct responses near zero (rather than the $30 \%$ that was found).
} 


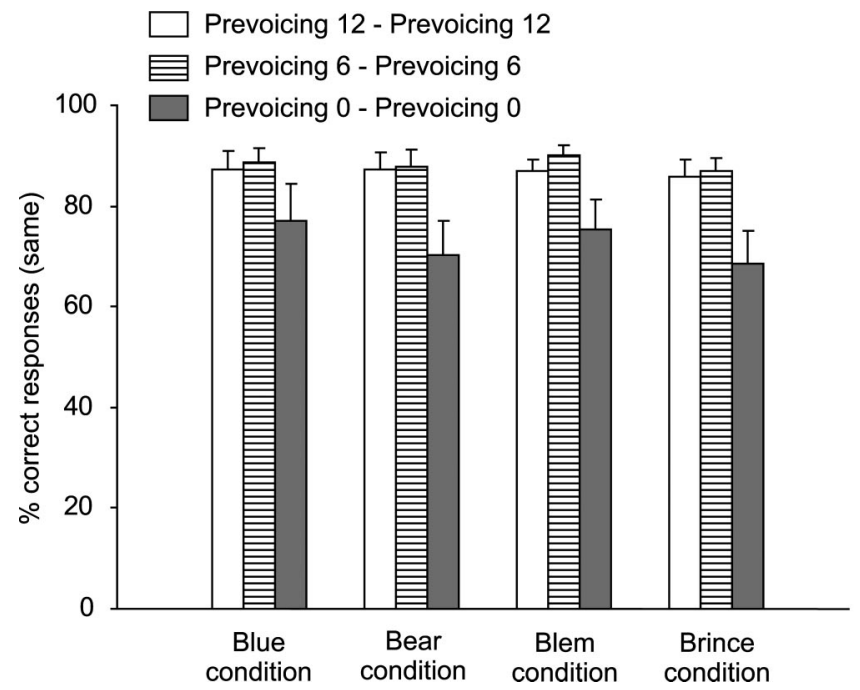

Figure 5. Mean percentage correct "same" responses in Experiment 3 for each of the identical pairs, plotted separately for each of the four lexical status conditions. Error bars indicate standard errors.

HSD test on the six means of the interaction between prevoicing pair and lexical status of the voiceless counterpart showed that there was a significant difference between word and nonword voiceless counterparts only for the pairs with 12 versus 0 periods and 6 versus 0 periods. That is, performance was significantly better in the two pairs that contained one item without prevoicing (the unfilled and striped bars in Figure 6) when the voiceless counterpart was a word (bear and brince conditions) than when it was a nonword (blue and blem conditions). For the pairs with 12 versus 6 periods (the dark bars in Figure 6), however, there was no difference as a function of lexical status of the voiceless counterpart. In other words, it was only in the "different" pairs in which one of the members did not have prevoicing that the lexical status of the voiceless counterpart influenced the proportion of correct responses. For those pairs, listeners responded correctly more often when the voiceless counterpart was a word.

\section{Discussion}

Listeners were able to detect the differences among all three prevoicing conditions. As predicted, the difference between two items was easier to detect when one of the two items had no prevoicing than when both items had prevoicing. For the pairs with one unprevoiced item, discrimination was easier when the other item had 12 periods of prevoicing than when the other item had 6 periods of prevoicing. The most difficult difference to detect was between 12 and 6 periods of prevoicing. Nevertheless, listeners performed better than chance in all three cases.

Furthermore, the results show a clear effect of the lexical status of the voiceless counterpart. In the conditions with voiceless word competitors (bear and brince), fewer mistakes were made in the "different" pairs when one of the pairs had no prevoicing (12-0 and 6-0 periods) than in the conditions without voiceless word competitors (blue and blem). There was no difference between the conditions with and without voiceless word competitors for the "different" pairs with prevoicing (12-6 periods). In line with the priming results, this finding suggests that items with prevoicing do not strongly activate their voiceless competitors but that the same items without prevoicing do activate their voiceless competitors more substantially. This made it easier for listeners to discriminate between items with and without prevoicing when there was a voiceless word competitor. For example, it was easier for listeners to hear the difference between beer with 6 periods of prevoicing and beer without prevoicing (because of the activation of peer in the latter case) than to hear the difference between blauw with 6 periods of prevoicing and blauw without prevoicing (because plauw is not a word). The finding that there was no effect of the lexical status of the voiced counterparts on discrimination performance also corresponds well with the results of the priming experiment. The priming results showed that prevoicing variation did not substantially affect the degree of activation of the voiced counterparts. The voiced representations were strongly activated by all three prevoicing variations, that is, even when prevoicing was absent. The lexical status of the voiced counterpart thus did not help listeners to discriminate among the three variations of prevoicing.

\section{General Discussion}

The purpose of the present study was to investigate the effect on lexical access of prevoicing variation in Dutch initial plosives. The results of the cross-modal identity-priming experiments showed no latency differences between the effects of primes starting with plosives with 12 periods of prevoicing and those of items starting with plosives with 6 periods of prevoicing. In both cases the primes resulted in facilitation of lexical decisions to identical voiced targets in comparison to unrelated targets (Experiment 1). Apparently, these degrees of prevoicing result in clearly voiced plosives, and primes starting with either of these plosives activate identical targets almost equally (though there was a significant difference in error rates as a function of amount of prevoicing in

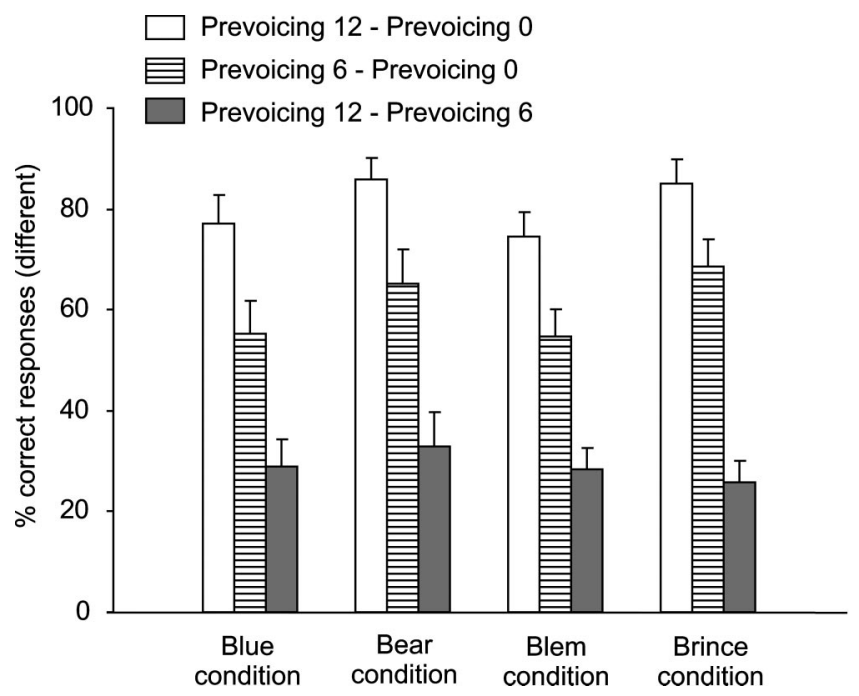

Figure 6. Mean percentage correct "different" responses in Experiment 3 for each of the pairs in which the two members differed in prevoicing duration, plotted separately for each of the four lexical status conditions. Error bars indicate standard errors. 
the bear condition only). The results of the identification phase in Experiment 1 indeed showed that these plosives are more or less unambiguously voiced. Items starting with these plosives therefore do not substantially activate word candidates with initial voiceless plosives, as was shown in Experiment 2. There was no difference in lexical decisions to voiceless targets preceded by primes with 12 periods and the same targets preceded by primes with 6 periods of prevoicing; in both cases there was no facilitation in comparison to the unrelated priming condition. This pattern of results may have been due to an inability of listeners to hear the difference between 12 and 6 periods of prevoicing, but the discrimination experiment (Experiment 3) indicated that listeners were in fact capable of distinguishing these two prevoicing durations from each other.

The same quantitative difference of 6 periods of prevoicing did influence lexical access when the prevoicing varied from 6 periods to 0 periods of prevoicing. Deleting the prevoicing takes away an important cue that the plosive is voiced. Although the identification results showed that in general the plosives without prevoicing were still perceived as voiced, the percentage of voiced responses was lower than for the plosives with prevoicing. The results of Experiments 1 and 2 indicate that primes starting with voiced plosives without prevoicing substantially activated both lexical candidates starting with voiced plosives and lexical candidates starting with voiceless plosives. Evidence of graded lexical activation by primes without prevoicing was observed only in specific conditions in the priming experiments, as a function of both the lexical status of prime and target and the degree of conflict between visual and auditory information (see earlier discussion). Nevertheless, it is clear that the acoustic information in primes without prevoicing is somewhat ambiguous; although the remaining acoustic cues favored voiced plosives and hence words beginning with those consonants, the absence of prevoicing also resulted in activation of voiceless plosives and words beginning with the corresponding consonants.

The discrimination experiment confirmed that plosives without prevoicing result in different lexical activation patterns from those caused by plosives with prevoicing. Listeners were able to discriminate among all three prevoicing durations, but their accuracy depended not only on the size of the difference but also on the presence of a token without prevoicing (the difference between 12 and 6 periods of prevoicing was harder to detect than that between 6 and 0 periods). Accuracy also depended on the lexical competitor environment, but only if one of the tokens had no prevoicing (the difference between 6 and 0 periods of prevoicing was easier to detect when there was a voiceless word competitor than when there was not). These results again indicate that tokens with plosives without prevoicing substantially activate both word candidates starting with voiced plosives and word candidates starting with voiceless plosives.

Overall, the three experiments show that the deletion of prevoicing has stronger effects on lexical access in Dutch than differences in the duration of prevoicing. When we compare these results with those of Andruski et al. (1994) in English, it might appear that there is a cross-linguistic difference in the influence of the competitor environment: Andruski et al. (who investigated effects of positive VOT variations in voiceless plosives) did not find a significant effect of the presence of a voiced word competitor, whereas we (investigating negative VOT variations in voiced plosives) did find effects of the presence of a voiceless word competitor in the brince and bear conditions. There is, however, no cross-linguistic difference here. We did not find any competitor effects in the lexical status conditions that correspond to the conditions tested by Andruski et al. (the blue condition with voiced targets and the bear condition with voiced targets). Furthermore, conditions in which we did find competitor effects were not tested by Andruski et al.: There could be no associated targets for nonword primes, and they did not measure the activation of the associate of the competitor (e.g., wolf as target when the prime was pear).

When we compare the results of the studies further, however, two interesting differences emerge. First, in Dutch, no reliable graded priming effects were found as a result of variation in negative VOT (6 or 12 periods of prevoicing), whereas in English, graded effects were found as a result of variation in positive VOT (unaltered or with VOT shortened by two thirds $[-2 / 3$ VOT]). Second, in contrast to the variation in the duration of prevoicing, the deletion of prevoicing strongly affects lexical activation in Dutch. Note that the equivalent case in English (i.e., deleting all aspiration and thus making the VOT zero) has not been tested. Note also that although prevoicing can occur in English, particularly in slow or careful speech (e.g., Docherty, 1992; Smith, 1978), the effect of prevoicing variability on lexical access in English has not been tested. Nevertheless, it is interesting to observe that the deletion of prevoicing in Dutch resulted in weaker graded effects than shortening positive VOT in English. Recall that Andruski et al. (1994) found differences in lexical decision latencies to targets preceded by related primes with unaltered VOT and $-2 / 3$ VOT, whereas the present priming experiments showed no difference in lexical decision latencies to voiced word targets preceded by identical voiced primes with prevoicing and without prevoicing. The effect of VOT shortening in English thus seems to result in stronger effects on lexical access than the deletion of prevoicing in Dutch does. Nevertheless, we did find clear indications that the absence of prevoicing resulted in substantial activation of voiceless word candidates in addition to activation of voiced word candidates.

Although both studies address the same basic question, there are some important differences between them that may account for these different findings. First, different experimental paradigms were used: Whereas Andruski et al. (1994) made use of the associative priming task in the auditory modality, we made use of the cross-modal identity-priming task. One might suggest that the lexical competition process plays a more important role in identity priming than in associative priming. The latter task could thus be more sensitive to graded lexical activation. However, van Alphen (2000) found a pattern of results similar to the one observed here using a cross-modal associative priming task with the items of the blue condition. No differences were found in lexical decisions to targets like roos (rose) between priming conditions in which the related prime bloem (flower) started with 12 or 6 periods of prevoicing and a condition in which the same prime had no prevoicing. All three primes resulted in the same amount of facilitation (in comparison to an unrelated prime). Furthermore, Utman et al. (2000) found graded effects of VOT variation in English using within-modality identity priming similar to those found by Andruski et al. Finally, McMurray et al. (2002) found graded effects of English VOT variation on lexical access while using yet another paradigm (eye tracking). This suggests that the difference 
between the Dutch and English findings should be sought in differences in the languages rather than in the experimental paradigms.

To understand the different patterns found in the English studies and the present study, one must focus on the differences in VOT between English and Dutch. Although VOT in both languages refers to the same temporal relation-namely, the moment in time that the vocal cords start vibrating in relation to the moment in time that the closure is released-acoustically and perceptually, VOT in the two languages is very different. In English, average VOTs of voiced and voiceless plosives both fall in the positive VOT range. Voiced plosives usually have a small positive VOT (roughly equal to the duration of the plosive burst), whereas voiceless plosives have a larger positive VOT (the combined duration of the plosive burst and the following aspiration). A large amount of research has shown that English listeners are very sensitive to variation in positive VOT and to the presence or absence of aspiration (Lotz et al., 1960). With respect to VOT, a small difference can abruptly change the proportion of responses from one voicing category to the other (Liberman, Harris, Eimas, Lisker, \& Bastian, 1961), and the placement of the voicing boundary and the location of the best exemplars on the VOT continuum depend on speaking rate (Green \& Miller, 1985; Miller, 1981; Miller \& Liberman, 1979; Miller \& Volaitis, 1989; Summerfield, 1981). The boundary between voiced and voiceless plosives in terms of VOT is therefore not fixed but varies on a continuous scale (see also Repp \& Liberman, 1987). Note that it is likely that prevoicing in Dutch also varies with speaking rate, but we controlled for any speaking-rate effects in this study by holding vowel duration in the primes constant.

In contrast to English, the main cue for the voicing distinction in Dutch is the presence or absence of voicing during the closure. All initial plosives with prevoicing tested in van Alphen and Smits (2004) were perceived as being voiced. That study reported two further observations that are relevant here. First, the duration of prevoicing varied considerably within and among speakers. Second, in apparent conflict with the finding that prevoicing is the primary cue to the voicing distinction, prevoicing is frequently not produced. No less than $25 \%$ of the voiced tokens in the sample of 640 utterances were produced without prevoicing. Nevertheless, the majority of these voiced tokens without prevoicing were still perceived as voiced. As discussed earlier, other acoustic cues signaled that the plosive was voiced.

These acoustic and perceptual differences between VOT in English and VOT in Dutch could serve as an explanation for the contrast between the findings of Andruski et al. (1994), Utman et al. (2000), and McMurray et al. (2002) and those of the present study. Small differences in amount of VOT seem to be more important in English than in Dutch, and the word recognition system accordingly seems to treat VOT variations differently in the two languages. Because in Dutch the most important cue is the presence or absence of prevoicing, it seems very plausible that Dutch listeners learn to ignore differences in the amount of prevoicing that is present. Keating, Mikos, and Ganong (1981) made the same suggestion about perception of initial plosives in Polish, a language that, like Dutch, makes a contrast between voiced plosives that have negative VOTs and voiceless unaspirated plosives that have positive VOTs. In contrast, as Keating et al. also suggested, English listeners should be very sensitive to gradient differences in positive VOT, because those differences carry important information for the distinction between voiced and voiceless plosives.

Furthermore, Dutch listeners ought also to have learned that a plosive without prevoicing could still be voiced. After all, Dutch listeners have often encountered words starting with plosives without prevoicing that should have started with voiced plosives (e.g., hearing blauw without prevoicing). However, because most plosives without prevoicing they encounter are actually voiceless, Dutch listeners should not ignore the presence or absence of prevoicing. The results of the current study show that listeners are indeed sensitive to this difference. When prevoicing is absent, both voiced and voiceless word candidates are activated. In contrast, there is no similar kind of ambiguity in VOT in English natural speech. English listeners will have rarely if ever encountered words starting with plosives without a positive VOT that should have been voiceless according to the lexicon. It would therefore be absurd if English listeners were to treat plosives with zero VOT as voiceless.

Both the English and Dutch word recognition systems thus seem to be sensitive to VOT variation that provides important information for the distinction between voiced and voiceless plosives. In Dutch the presence or absence of prevoicing is most important, whereas in English the duration of the positive VOT is important. This comparison between Dutch and English indicates that language-specific information about the relative importance of different types of phonetic variation is acquired by the wordrecognition system. We suggest that phonetically relevant information, as defined by native language experience, carries more weight at the lexical level. Prelexical processing therefore ensures that information that helps to distinguish between phonemes and thus between words (such as the presence or absence of prevoicing in Dutch and the amount of positive VOT in English) will affect lexical access more strongly than information that is less relevant.

One way in which this could be achieved is if abstract, prototypical representations of the speech sounds in the listener's native language acted to mediate between low-level acoustic processing and lexical processing. Experience with the native language would allow tuning of these representations to more relevant phonetic detail. Note that, as argued elsewhere (e.g., McQueen et al., 1999), such prelexical representations should operate in cascade, sending information continuously to the lexical level to modulate lexical activation. Note also that such a view is consistent with demonstrations that the surface form of spoken words is retained in memory (e.g., Goldinger, 1996), if that information is not discarded during prelexical processing. Finally, note that this view offers a framework for thinking about how other types of finegrained phonetic detail can influence lexical access. Several studies have shown that differences in syllable or segment duration can influence segmentation of continuous speech and hence lexical activation (e.g., Davis et al., 2002; Gow \& Gordon, 1995; Salverda et al., 2003; Shatzman \& McQueen, in press; Spinelli et al., 2003; Tabossi et al., 2000). We would argue that these effects also reflect a prelexical process of abstraction. But in these cases there is computation of suprasegmental structure (prosodic boundaries), which can be used to facilitate lexical segmentation (rather than abstraction of segmental prototypes, as in the account of VOT effects). In both cases, language experience triggers the system to 
learn what phonetic detail in the acoustic input is most valuable for word recognition.

In conclusion, we have shown that Dutch listeners are sensitive to variations in prevoicing in Dutch initial voiced plosives, and that the effects of VOT variation on lexical access depend on the nature of that variation. The difference between the presence and absence of prevoicing has a stronger effect on lexical access than a change in the amount of prevoicing. The differences between these two types of VOT variation can be explained in terms of the informational value of these variations. The recognition system appears to be more sensitive to variation in the speech signal that is more important for lexical distinctions. The presence or absence of prevoicing appears to be the primary cue for the voicing distinction in Dutch, whereas variation in the exact duration of prevoicing is not very important. As a result, a difference between the presence and absence of prevoicing influences lexical access more strongly than a difference in the amount of prevoicing. We have therefore shown that although phonetic fine detail can influence lexical processing in a continuous and graded fashion, such effects are conditional on how relevant the fine-grained detail is for word recognition. The comparison between VOT effects on lexical access in Dutch and English indicates that the informational value of VOT variation varies between these two languages. Experience with a language triggers the recognition system to learn what phonetic detail in the acoustic input is most valuable for the recognition of words in that particular language. As a result, lexical activation is modulated as a function of the informational value of the phonetic detail in the speech signal.

\section{References}

Andruski, J. E., Blumstein, S. E., \& Burton, M. (1994). The effect of subphonetic differences on lexical access. Cognition, 52, 163-187.

Baayen, H., Piepenbrock, R., \& Gulikers, L. (1995). The CELEX lexical database [CD-ROM]. Philadelphia: Linguistic Data Consortium, University of Pennsylvania.

Connine, C. M., Blasko, D. G., \& Titone, D. (1993). Do the beginnings of spoken words have a special status in auditory word recognition? Journal of Memory and Language, 32, 193-210.

Connine, C. M., Titone, D., Deelman, T., \& Blasko, D. (1997). Similarity mapping in spoken word recognition. Journal of Memory and Language, 37, 463-480.

Cutler, A., van Ooijen, B., \& Norris, D. (1999). Vowels, consonants and lexical activation. In J. J. Ohala, Y. Hasegawa, M. Ohala, D. Granville, $\&$ A. C. Bailey (Eds.), Proceedings of the 14th International Congress of Phonetic Sciences (Vol. 3, pp. 2053-2056). Berkeley: University of California.

Dahan, D., Magnuson, J. S., Tanenhaus, M. K., \& Hogan, E. M. (2001). Subcategorical mismatches and the time course of lexical access: Evidence for lexical competition. Language and Cognitive Processes, 16, 507-534.

Davis, M. H., Marslen-Wilson, W. D., \& Gaskell, M. G. (2002). Leading up the lexical garden-path: Segmentation and ambiguity in spoken word recognition. Journal of Experimental Psychology: Human Perception and Performance, 28, 218-244.

Docherty, G. J. (1992). The timing of voicing in English obstruents. Berlin, Germany: Foris Publications.

Frauenfelder, U. H., Scholten, M., \& Content, A. (2001). Bottom-up inhibition in lexical selection: Phonological mismatch effects in spoken word recognition. Language and Cognitive Processes, 16, 583-607.

Goldinger, S. D. (1996). Words and voices: Episodic traces in spoken word identification and recognition memory. Journal of Experimental Psychology: Learning, Memory, and Cognition, 22, 1166-1183.

Gow, D. W. (2002). Does English coronal place assimilation create lexical ambiguity? Journal of Experimental Psychology: Human Perception and Performance, 28, 163-179.

Gow, D. W., \& Gordon, P. C. (1995). Lexical and prelexical influences on word segmentation: Evidence from priming. Journal of Experimental Psychology: Human Perception and Performance, 21, 344-359.

Green, K. P., \& Miller, J. L. (1985). On the role of visual rate information in phonetic perception. Perception \& Psychophysics, 38, 269-276.

Keating, P. A., Mikos, M. J., \& Ganong, W. F. (1981). A cross-language study of range of voice onset time in the perception of initial stop voicing. Journal of the Acoustical Society of America, 70, 1261-1271.

Keppel, G. (1982). Design and analysis: A researcher's handbook. Englewood Cliffs, NJ: Prentice Hall.

Liberman, A. M., Harris, K. S., Eimas, P., Lisker, L., \& Bastian, J. (1961). An effect of learning on speech perception: The discrimination of durations of silence with and without phonemic significance. Language and Speech, 4, 175-195.

Lisker, L., \& Abramson, A. S. (1970). The voicing dimension: Some experiments in comparative phonetics. In Proceedings of the Sixth International Congress of Phonetic Sciences (pp. 563-567). Prague, Czech Republic: Academia.

Lotz, J., Abramson, A. S., Gerstman, L. J., Ingemann, F., \& Nemser, W. J. (1960). The perception of stops by speakers of English, Spanish, Hungarian, and Thai: A tape-cutting experiment. Language and Speech, 3, $71-76$.

Macmillan, N. A., \& Creelman, C. D. (1991). Detection theory: A user's guide. Cambridge, England: Cambridge University Press.

Marslen-Wilson, W., Moss, H. E., \& van Halen, S. (1996). Perceptual distance and competition in lexical access. Journal of Experimental Psychology: Human Perception and Performance, 22, 1376-1392.

Marslen-Wilson, W. D., Nix, A., \& Gaskell, M. G. (1995). Phonological variation in lexical access: Abstractness, inference and English place assimilation. Language and Cognitive Processes, 10, 285-308.

Marslen-Wilson, W., \& Warren, P. (1994). Levels of perceptual representation and process in lexical access: Words, phonemes, and features. Psychological Review, 101, 653-675.

Marslen-Wilson, W., \& Zwitserlood, P. (1989). Accessing spoken words: On the importance of word onsets. Journal of Experimental Psychology: Human Perception and Performance, 15, 576-585.

McMurray, B., Tanenhaus, M. K., \& Aslin, R. N. (2002). Gradient effects of within-category phonetic variation on lexical access. Cognition, 86, B33-B42.

McQueen, J. M. (2005). Speech perception. In K. Lamberts \& R. Goldstone (Eds.), The handbook of cognition (pp. 255-275). London: Sage.

McQueen, J. M., Norris, D., \& Cutler, A. (1999). Lexical influence in phonetic decision making: Evidence from subcategorical mismatches. Journal of Experimental Psychology: Human Perception and Performance, 25, 1363-1389.

Milberg, W., Blumstein, S., \& Dworetzky, B. (1988). Phonological factors in lexical access: Evidence from an auditory lexical decision task. Bulletin of the Psychonomic Society, 26, 305-308.

Miller, J. L. (1981). Effects of speaking rate on segmental distinctions. In P. D. Eimas \& J. L. Miller (Eds.), Perspectives on the study of speech (pp. 39-74). Hillsdale, NJ: Erlbaum.

Miller, J. L., \& Liberman, A. M. (1979). Some effects of later-occurring information on the perception of stop consonant and semivowel. Per ception \& Psychophysics, 25, 457-465.

Miller, J. L., \& Volaitis, L. E. (1989). Effects of speaking rate on the perceived internal structure of phonetic categories. Perception \& Psy chophysics, 46, 505-512.

Radeau, M., Segui, J., \& Morais, J. (1994). The effect of overlap position in phonological priming between spoken words. In Proceedings of the 
1994 International Conference on Spoken Language Processing (Vol. 3, pp. 1419-1422). Yokohama, Japan: Acoustical Society of Japan.

Repp, B. H., \& Liberman, A. M. (1987). Phonetic category boundaries are flexible. In S. R. Harnad (Ed.), Categorical perception (pp. 89-112). Cambridge, England: Cambridge University Press.

Salverda, A. P., Dahan, D., \& McQueen, J. M. (2003). The role of prosodic boundaries in the resolution of lexical embedding in speech comprehension. Cognition, 90, 51-89.

Shatzman, K. B., \& McQueen, J. M. (in press). Segment duration as a cue to word boundaries in spoken-word recognition. Perception \& Psychophysics.

Slowiaczek, L. M., McQueen, J. M., Soltano, E. G., \& Lynch, M. (2000). Phonological representations in prelexical speech processing: Evidence from form-based priming. Journal of Memory and Language, 43, 530-560.

Smith, B. (1978). Effects of place of articulation and vowel environment on voiced stop consonant production. Glossa, 12, 163-175.

Spinelli, E., McQueen, J. M., \& Cutler, A. (2003). Processing resyllabified words in French. Journal of Memory and Language, 48, 233-254.

Streeter, L. A., \& Nigro, G. N. (1979). The role of medial consonant transitions in word perception. Journal of the Acoustical Society of America, 65, 1533-1541.

Studebaker, G. A. (1985). A "rationalized" arcsine transform. Journal of Speech and Hearing Research, 28, 455-462.
Summerfield, A. Q. (1981). Articulatory rate and perceptual constancy in phonetic perception. Journal of Experimental Psychology: Human Perception and Performance, 7, 1074-1095.

Tabossi, P., Collina, S., Mazzetti, M., \& Zoppello, M. (2000). Syllables in the processing of spoken Italian. Journal of Experimental Psychology: Human Perception and Performance, 26, 758-775.

Utman, J. A., Blumstein, S. E., \& Burton, M. W. (2000). Effects of subphonetic and syllable structure variation on word recognition. Perception \& Psychophysics, 62, 1297-1311.

van Alphen, P. M. (2000). Does subcategorical variation influence lexical access? In A. Cutler, J. McQueen, \& R. Zondervan (Eds.), Proceedings of SWAP: Workshop on Spoken Word Access Processes (pp. 55-58). Nijmegen, the Netherlands: MPI for Psycholinguistics.

van Alphen, P. M., \& Smits, R. (2004). Acoustical and perceptual analysis of the voicing distinction in Dutch initial plosives: The role of prevoicing. Journal of Phonetics, 32, 455-491.

van der Lugt, A. (1999). From speech to words (MPI Series in Psycholinguistics No. 13). Doctoral dissertation, University of Nijmegen, Nijmegen, the Netherlands.

Whalen, D. H. (1984). Subcategorical phonetic mismatches slow phonetic judgments. Perception \& Psychophysics, 35, 49-64.

Whalen, D. H. (1991). Subcategorical phonetic mismatches and lexical access. Perception \& Psychophysics, 50, 351-360. 


\section{Appendix}

Materials for Experiments 1, 2, and 3

\begin{tabular}{|c|c|c|c|c|c|c|c|c|c|c|c|}
\hline \multicolumn{12}{|c|}{ Lexical status condition } \\
\hline \multicolumn{3}{|c|}{ Blue } & \multicolumn{3}{|c|}{ Bear } & \multicolumn{3}{|c|}{ Blem } & \multicolumn{3}{|c|}{ Brince } \\
\hline $\begin{array}{l}\text { Voiced } \\
\text { word }\end{array}$ & $\begin{array}{l}\text { Voiceless } \\
\text { nonword }\end{array}$ & $\begin{array}{c}\text { Unrelated } \\
\text { word }\end{array}$ & $\begin{array}{l}\text { Voiced } \\
\text { word }\end{array}$ & $\begin{array}{l}\text { Voiceless } \\
\text { word }\end{array}$ & $\begin{array}{l}\text { Unrelated } \\
\text { word }\end{array}$ & $\begin{array}{l}\text { Voiced } \\
\text { nonword }\end{array}$ & $\begin{array}{l}\text { Voiceless } \\
\text { nonword }\end{array}$ & $\begin{array}{c}\text { Unrelated } \\
\text { nonword }\end{array}$ & $\begin{array}{c}\text { Voiced } \\
\text { nonword }\end{array}$ & $\begin{array}{l}\text { Voiceless } \\
\text { word }\end{array}$ & $\begin{array}{c}\text { Unrelated } \\
\text { nonword }\end{array}$ \\
\hline beek & peek & beurs & baal* & paal & bef & baag & paag & beim & baus & paus & bolm \\
\hline beest & peest & brug & baard & paard & broek & bans & pans & bluif & bech & pech & bift \\
\hline berg & perg & blond & baars & paars & bluf & baun & paun & bork & bees & pees & briek \\
\hline berm & perm & buit & bad & pad & blij & bemp & pemp & blans & bels* & pels & bruig \\
\hline biels* & piels & beits & bak & pak & blok & beus & peus & bamp & bens & pens & bramp \\
\hline big* & pig & brons & band & pand & blik & biens & piens & braap & bers* & pers & bluig \\
\hline blauw & plauw & buurt & beer & peer & breuk & bimp & pimp & buif & biek & piek & braalf \\
\hline bleek & pleek & brand & berk & perk & brits & blaaf* & plaaf & broen & bijn & pijn & brog \\
\hline blits* & plits & brom & beuk & peuk & bruut & blarp & plarp & beuf & bijp & pijp & brong \\
\hline bloem & ploem & baan & beul & peul & biecht & bleep & pleep & boof & blaats & plaats & barf \\
\hline blos & plos & bars & bijl & pijl & boon & blem & plem & burf & blak & plak & beift \\
\hline boer & poer & barst & bink* & pink & bres & blimp & plimp & beeuw & blant & plant & boest \\
\hline bok* & pok & bruid & blaag* & plaag & broom & boens & poens & beeg & blein & plein & bruf \\
\hline bonk* & ponk & brink & blad & plat & braaf & boop & poop & baug & blens & plens & birf \\
\hline boor & poor & blaar & blank & plank & beurt & borf & porf & bem & blons* & plons & brieg \\
\hline braam & praam & boeg & boef* & poef & bes & braas & praas & beig & blooi & plooi & buint \\
\hline brein & prein & boog & boel & poel & bruin & bralm & pralm & bien & bluim & pluim & bieg \\
\hline brief & prief & boom & boord & poort & bloed & braup & praup & bieft & bluis & pluis & brimp \\
\hline bries* & pries & blaas & boos* & poos & breed & breeg & preeg & bilm & bluk & pluk & braft \\
\hline broer & proer & bos & boot & poot & beeld & breum & preun & baust & boes & poes & blauk \\
\hline brok & prok & bloot & bot & pot & bang & brim & prim & blaap & bols* & pols & brump \\
\hline bron & pron & bloei & bouw & pauw & bar & broeg & proeg & baaf & bret & pret & balp \\
\hline brood & prood & balk & brij* & prei & blaam & brolf & prolf & baam & briem & priem & blook \\
\hline bros & pros & bult & bril & pril & bank & broon & proon & buuft & brins & prins & baats \\
\hline buil* & puil & brie & brul* & prul & bout & bruif* & pruif & blig & broef & proef & bleug \\
\hline buis* & puis & bom & bul & pul & branche & buip & puip & blors & buin & puin & blerk \\
\hline burcht & purcht & broos & buur & puur & borst & buug & puug & blef & bunt & punt & bref \\
\hline damp & tamp & dief & dak & tak & duim & daaf & taaf & dirp & daai* & taai & drelp \\
\hline darm & tarm & dwaas & dam & tam & drang & dars & tars & dift & dand & tand & dwes \\
\hline deur & teur & drie & das & tas & dek & deig & teig & duust & deil* & teil & daft \\
\hline dicht* & ticht & drank & dof & tof & drift & delm & telm & dreeg & dekst & tekst & dramp \\
\hline dons & tons & duik & dol & tol & druif & deust & teust & dorf & dest & test & drak \\
\hline dorp & torp & dag & dolk & tolk & dijk & diest & tiest & daam & dint & tint & draast \\
\hline draad & traad & doel & dooi* & tooi & deuk & dreek* & treek & doeng & dong* & tong & def \\
\hline draak & traak & douche & doorn* & toorn & dwang & drens & trens & diem & doost & toost & drauf \\
\hline drum & trum & deeg & dop & top & dreum & droof & troof & dweik & drein* & trein & dulf \\
\hline duif & tuif & doek & dor & tor & draf & drooi* & trooi & daust & droon & troon & deets \\
\hline dwars & twars & dood & drol & trol & duw & duip* & tuip & draam & drui & trui & dosp \\
\hline dweil & tweil & draai & duin & tuin & deugd & dwaag* & twaag & doemp & dulp & tulp & diecht \\
\hline dwerg & twerg & doof & duit* & tuit & disk & dwam & twam & dooks & dwijg* & twijg & deuf \\
\hline
\end{tabular}

Note. Item sets marked with an asterisk were not included in any analyses. 